Supporting Information for

\title{
Strong $\pi$-Backbonding Enables Record Magnetic Exchange Coupling Through Cyanide
}

Juan A. Valdez-Moreira, Agnes E. Thorarinsdottir, Jordan A. DeGayner, Sean A. Lutz, ChunHsing Chen, Yaroslav Losovyj, Maren Pink, T. David Harris, and Jeremy M. Smith 


\section{Table of Contents}

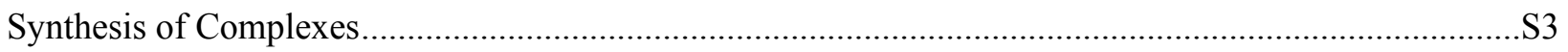

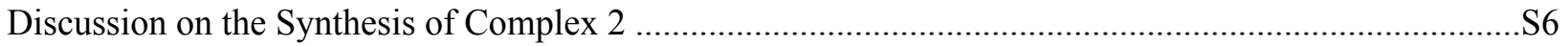

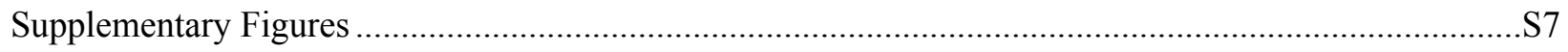

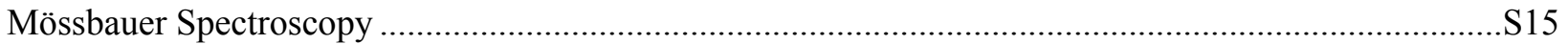



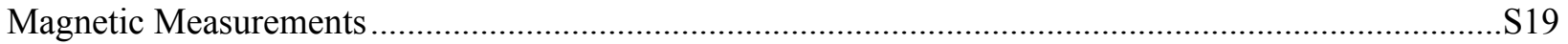

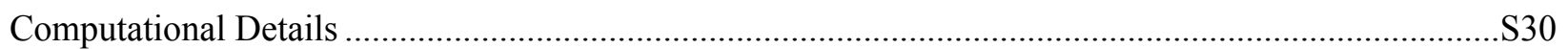

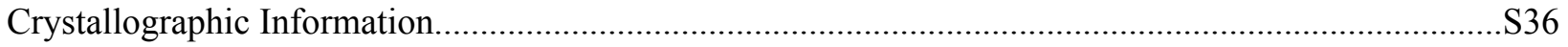

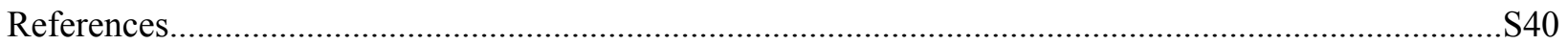




\section{Synthesis of Complexes}

General Considerations. All manipulations involving air- or moisture sensitive compounds and their preparation were performed under an inert atmosphere of dry $\mathrm{N}_{2}$ by standard Schlenk techniques or in an MBraun glovebox. Glassware was oven-dried for at least $12 \mathrm{~h}$ at $140{ }^{\circ} \mathrm{C}$ before use. Celite was oven-dried for $12 \mathrm{~h}$ at $140{ }^{\circ} \mathrm{C}$. All solvents were purchased from Sigma-Aldrich, and used after being dried using alumina and Q5 drying columns. The compounds $\mathrm{PhB}\left({ }^{\mathrm{t}} \mathrm{BuIm}\right)_{3} \mathrm{FeCl},{ }^{1}$ and $\mathrm{Mo}\left(\mathrm{N}^{\mathrm{t}} \mathrm{Bu}\left(3,5-\mathrm{C}_{6} \mathrm{H}_{3} \mathrm{Me}_{2}\right)\right)_{3}\left(\mathrm{Mo}\left(\mathrm{N}^{\mathrm{t} B u A r}\right)_{3}\right)^{2}$ were prepared according to literature procedures, while $\mathrm{NaOMe}$ was purified following a literature procedure. ${ }^{3}$ All other chemicals were purchased from commercial vendors and used as received. Deuterated solvents were purchased from Cambridge Isotope Laboratories, Inc. $\mathrm{C}_{6} \mathrm{D}_{6}$ and THF- $d_{8}$ were degassed and stored over molecular sieves for at least one day before use. ${ }^{1} \mathrm{H}$ NMR spectroscopic measurements of air and moisture sensitive compounds were made in J-Young NMR tubes, with the spectroscopic data recorded on Varian $400 \mathrm{MHz}$ NMR spectrometers at $25^{\circ} \mathrm{C}$. IR spectra were recorded with a Perkin Elmer spectrophotometer. Cyclic voltammograms were measured using a $\mathrm{CH}$ Instruments Model 600B Series Electrochemical Analyzer/Workstation. UV-visible spectra were recorded with an Agilent Cary $60 \mathrm{UV}$-visible spectrometer. Elemental analysis was conducted by Midwest Microlab, LLC (Indianapolis, IN).

Preparation of $\mathbf{P h B}\left({ }^{\mathrm{t}} \mathrm{BuIm}\right)_{3} \mathrm{FeOCH}_{3}$. In a $20 \mathrm{~mL}$ scintillation vial, $\mathrm{PhB}\left({ }^{\mathrm{t}} \mathrm{BuIm}\right)_{3} \mathrm{FeCl}(200 \mathrm{mg}$, $0.364 \mathrm{mmol}$ ) was dissolved in THF (4 mL). A suspension of NaOMe (98 mg, $1.82 \mathrm{mmol})$ in THF $(4 \mathrm{~mL})$ was added to the solution. The reaction mixture was stirred at room temperature for $48 \mathrm{~h}$, and the solvent was evaporated under vacuum. The solid was extracted into toluene and filtered through a frit charged with Celite. The filtrate was dried under vacuum, leaving a white powder (93 mg, 46\% yield). Crystals suitable for X-ray diffraction were grown by layering n-pentane onto 
a THF solution at $-35{ }^{\circ} \mathrm{C} .{ }^{1} \mathrm{H}$ NMR $\left(\mathrm{C}_{6} \mathrm{D}_{6}, 400 \mathrm{MHz}\right) \delta(\mathrm{ppm}) 75(3 \mathrm{H}, \mathrm{Im}-\mathrm{H}), 74(3 \mathrm{H}, \mathrm{Im}-\mathrm{H}), 5$ $\left(2 \mathrm{H}, \mathrm{B}\left(\mathrm{C}_{6} \mathrm{H}_{5}\right) o / m-\mathrm{H}\right), 25\left(2 \mathrm{H}, \mathrm{B}\left(\mathrm{C}_{6} \mathrm{H}_{5}\right) o / m-\mathrm{H}\right), 21\left(1 \mathrm{H}, \mathrm{B}\left(\mathrm{C}_{6} \mathrm{H}_{5}\right) p-\mathrm{H}\right),-31\left(27 \mathrm{H}, \mathrm{C}\left(\mathrm{CH}_{3}\right)_{3}\right)$.

Preparation of $\mathbf{P h B}\left({ }^{\mathrm{t}} \mathrm{BuIm}\right)_{3} \mathbf{F e F}$ (1). A Schlenk flask was charged with, trifluoromethyltrimethylsilane (26 mg, $0.184 \mathrm{mmol}), \mathbf{P h B}\left({ }^{\mathrm{t}} \mathbf{B u I m}\right)_{3} \mathbf{F e O C H}(100 \mathrm{mg}, 0.184$ mmol), and THF (10 mL). The solution was heated at reflux for $12 \mathrm{~h}$. The flask was brought back into the glovebox, the solvent was evaporated under vacuum to obtain a brown solid, which was washed with diethyl ether ( $73 \mathrm{mg}, 74 \%$ yield). Crystals suitable for X-ray diffraction were grown by layering n-pentane onto a THF solution at $-35{ }^{\circ} \mathrm{C} .{ }^{1} \mathrm{H} N M R\left(\mathrm{C}_{6} \mathrm{D}_{6}, 400 \mathrm{MHz}\right) \delta(\mathrm{ppm}) 79(3 \mathrm{H}$, Im-H), $71(3 \mathrm{H}, \mathrm{Im}-\mathrm{H}), 49\left(2 \mathrm{H}, \mathrm{B}\left(\mathrm{C}_{6} \mathrm{H}_{5}\right) o / m-\mathrm{H}\right), 24\left(2 \mathrm{H}, \mathrm{B}\left(\mathrm{C}_{6} \mathrm{H}_{5}\right) o / m-\mathrm{H}\right), 21\left(1 \mathrm{H}, \mathrm{B}\left(\mathrm{C}_{6} \mathrm{H}_{5}\right) p-\mathrm{H}\right)$, $-24\left(27 \mathrm{H}, \mathrm{C}\left(\mathrm{CH}_{3}\right)_{3}\right)$. Anal. Cald. for 1: C 60.92, H 7.20, N 15.79; Found: C 60.87, H 7.47, N 15.52 .

Preparation of PhB('BuIm) ${ }_{3}$ FeCN (2) In a $20 \mathrm{ml}$ scintillation vial, 1 (480 mg, $0.902 \mathrm{mmol}$ ) was dissolved in THF $(10 \mathrm{~mL})$, trimethylsilyl cyanide $(90 \mathrm{mg}, 0.902 \mathrm{mmol})$ was added to the solution containing 1 . The mixture was stirred at room temperature for $10 \mathrm{~min}$, and the solvent was removed under vacuum to yield a brown solid ( $408 \mathrm{mg}, 84 \%$ yield). Crystals suitable for X-ray diffraction were grown by layering n-pentane onto a THF solution at $-35{ }^{\circ} \mathrm{C} .{ }^{1} \mathrm{H}$ NMR $\left(\mathrm{C}_{6} \mathrm{D}_{6}, 400 \mathrm{MHz}\right) \delta$ (ppm) $74(3 \mathrm{H}, \mathrm{Im}-\mathrm{H}), 50(3 \mathrm{H}, \mathrm{Im}-\mathrm{H}), 30\left(2 \mathrm{H}, \mathrm{B}\left(\mathrm{C}_{6} \mathrm{H}_{5}\right) o / m-\mathrm{H}\right), 16\left(2 \mathrm{H}, \mathrm{B}\left(\mathrm{C}_{6} \mathrm{H}_{5}\right) o / m-\mathrm{H}\right), 14(1 \mathrm{H}$, $\left.\mathrm{B}\left(\mathrm{C}_{6} \mathrm{H}_{5}\right) p-\mathrm{H}\right),-7\left(27 \mathrm{H}, \mathrm{C}\left(\mathrm{CH}_{3}\right)_{3}\right)$. IR (THF) $v_{\mathrm{CN}}=2056 \mathrm{~cm}^{-1}$ Anal. Cald. for 2-Me $3 \mathrm{SiCN}: \mathrm{C} 60.19$, H 7.42, N 17.55; Found: C 60.08, H 7.18, N 17.04.

Preparation of $\mathbf{P h B}\left({ }^{(} \mathrm{BuIm}\right)_{3} \mathbf{F e N C M o}\left(\mathbf{N}^{\mathrm{t} B u A r}\right)_{3}$ (3) In a $20 \mathrm{~mL}$ scintillation vial, 2 (362 mg, $0.671 \mathrm{mmol})$ was dissolved in THF $(10 \mathrm{~mL})$. A solution containing $\mathrm{Mo}\left(\mathrm{N}^{\mathrm{t} B u A r}\right)_{3}(419 \mathrm{mg}, 0.671$ mmol) in THF ( $5 \mathrm{~mL})$ was added to this solution. An immediate color change from dark brown to dark purple was observed. The purple solution was stirred for $30 \mathrm{~min}$ and the solvent was removed 
under vacuum to leave a dark purple powder. Dark purple X-ray quality crystals were grown from a 1:1 diethyl ether:n-pentane solution at $-35^{\circ} \mathrm{C}\left(356 \mathrm{mg}, 46 \%\right.$ yield) ${ }^{1} \mathrm{H}$ NMR (THF- $d_{8}, 400 \mathrm{MHz}$ ) $\delta(\mathrm{ppm}) 56(3 \mathrm{H}, \mathrm{Im}-\mathrm{H}), 55(3 \mathrm{H}, \mathrm{Im}-\mathrm{H}), 41\left(2 \mathrm{H}, \mathrm{B}\left(\mathrm{C}_{6} \mathrm{H}_{5}\right) o / m-\mathrm{H}\right), 21\left(2 \mathrm{H}, \mathrm{B}\left(\mathrm{C}_{6} \mathrm{H}_{5}\right) o / m-\mathrm{H}\right), 18$ $\left(1 \mathrm{H}, \mathrm{B}\left(\mathrm{C}_{6} \mathrm{H}_{5}\right) p-\mathrm{H}\right), 17\left(6 \mathrm{H}, \mathrm{C}_{6} \mathrm{H}_{3} \mathrm{Me}_{2} o-\mathrm{H}\right), 10\left(3 \mathrm{H}, \mathrm{C}_{6} \mathrm{H}_{3} \mathrm{Me}_{2} p-\mathrm{H}\right), 10\left(27 \mathrm{H}, \mathrm{C}\left(\mathrm{CH}_{3}\right)_{3}\right), 5(18 \mathrm{H}$, $\left.\mathrm{C}_{6} \mathrm{H}_{3} \mathrm{Me}_{2} \mathrm{CH}_{3}\right),-21\left(27 \mathrm{H}, \mathrm{C}\left(\mathrm{CH}_{3}\right)_{3}\right)$. IR (THF) $v_{\mathrm{CN}}=1793 \mathrm{~cm}^{-1}$. IR (KBr) $v_{\mathrm{CN}}=1773 \mathrm{~cm}^{-1}$. Anal. Cald. for 3: C 66.03, H 7.97, N 12.03; Found: C 65.83, H 8.41, N 11.90.

The ${ }^{1} \mathrm{H}$ NMR spectrum of $\mathbf{3}$ is distinct from those of the iron and molybdenum complexes, with no changes in the appearance of the spectrum over the range $0.5-5 \mathrm{mM}$ range (Figure S10). In addition, the cyclic voltammogram of $\mathbf{3}$ (Figure S11) shows two reversible waves $\left(E_{1 / 2}=-1.23 \mathrm{~V}\right.$ and $E_{1 / 2}=-2.50 \mathrm{~V} \mathrm{vs} \mathrm{Fc}^{+} / \mathrm{Fc}$ ), whereas the cyclic voltammogram of $\mathbf{2}$ reveals a single reversible cathodic wave $\left(E_{1 / 2}=-2.60 \mathrm{~V}\right)$ and $\mathrm{Mo}\left(\mathrm{N}^{\mathrm{t}} \mathrm{BuAr}\right)_{3}$ shows a single irreversible reductive process with $E_{\mathrm{p}, \mathrm{c}}=-2.9 \mathrm{~V} .{ }^{4}$ The combined characterization data provides no evidence for the dissociation of $\mathbf{3}$ in solution.

Reaction of $\mathrm{PhB}\left({ }^{(\mathrm{BuIm}){ }_{3} \mathrm{FeOCH}} \mathrm{OC}_{3}\right.$ or 1 with excess $\mathrm{Me}_{3} \mathrm{SiCN}$ (4) Addition of excess trimethylsilyl cyanide to a solution containing either $\mathbf{P h B}\left({ }^{\mathrm{t}} \mathbf{B u I m}\right)_{3} \mathbf{F e O C H} \mathbf{H}_{3}$ or $\mathbf{1}$ initially yields a pale purple solution that slowly turns to a pale yellow color. Spectroscopic and X-ray structural characterization reveals the formation of a diamagnetic six-coordinate complex $\mathrm{PhB}\left({ }^{(} \mathrm{BuIm}\right)_{3} \mathrm{FeCN}\left(\mathrm{CNSiMe}_{3}\right)_{2}$, which was not further characterized. ${ }^{1} \mathrm{H} \mathrm{NMR}\left(\mathrm{C}_{6} \mathrm{D}_{6}, 400 \mathrm{MHz}\right)$ $\delta(\mathrm{ppm}) 8.08\left(\mathrm{~d}, 2 \mathrm{H}, \mathrm{B}\left(\mathrm{C}_{6} \mathrm{H}_{5}\right) o / m-\mathrm{H}\right), 7.41(\mathrm{~s}, 2 \mathrm{H}, \mathrm{Im}-\mathrm{H}), 7.40\left(\mathrm{~s}, 1 \mathrm{H}, \mathrm{B}\left(\mathrm{C}_{6} \mathrm{H}_{5}\right) p-\mathrm{H}\right), 7.35(\mathrm{~m}$, $\left.2 \mathrm{H}, \mathrm{B}\left(\mathrm{C}_{6} \mathrm{H}_{5}\right) o / m-\mathrm{H}\right), 6.76(\mathrm{~s}, 2 \mathrm{H}, \mathrm{Im}-\mathrm{H}), 6.65(\mathrm{~s}, 1 \mathrm{H}, \mathrm{Im}-\mathrm{H}), 6.56(\mathrm{~s}, 1 \mathrm{H}, \mathrm{Im}-\mathrm{H}), 2.01(\mathrm{~s}, 18 \mathrm{H}$, $\left.\mathrm{C}\left(\mathrm{CH}_{3}\right)_{3}\right), 1.66\left(\mathrm{~s}, 9 \mathrm{H}, \mathrm{C}\left(\mathrm{CH}_{3}\right)_{3}\right), 0.19\left(\mathrm{~s}, 18 \mathrm{H}, \mathrm{Si}\left(\mathrm{CH}_{3}\right)_{3}\right)$. IR $(\mathrm{THF}) v_{\mathrm{CN}}=2091,2025,1959 \mathrm{~cm}^{-1}$. 


\section{Discussion on the Synthesis of Complex 2}

An unconventional synthesis of the iron monocyanide species (2) was required as there is no reaction between $\mathrm{PhB}\left({ }^{\mathrm{t}} \mathrm{BuIm}\right)_{3} \mathrm{FeCl}$ and typical cyanide sources $\left(\mathrm{KCN}, \mathrm{NaCN},\left(\mathrm{Bu}_{4} \mathrm{~N}\right) \mathrm{CN}\right)$. Based on the hypothesis that the lack of reaction was due to solubility issues, we investigated the use of a soluble source of cyanide, $\mathrm{Me}_{3} \mathrm{SiCN}$. Reaction of the silyl cyanide with equimolar amount of $\mathrm{PhB}\left({ }^{\mathrm{t}} \mathrm{BuIm}\right)_{3} \mathrm{FeCl}$ provided a $1: 1$ ratio of 4 and starting material. The new iron alkoxide $\left(\mathbf{P h B}\left({ }^{\mathrm{t}} \mathrm{BuIm}\right)_{3} \mathrm{FeOCH}_{3}\right)$ was therefore synthesized to increase the affinity for reaction with organosilicon reagents. However, the reaction of this complex and $\mathrm{Me}_{3} \mathrm{SiCN}$ also resulted in a 1:1 mixture of starting material and 4. Seeking to further increase the affinity for organosilicon reagents, we prepared the new iron fluoride (1). Gratifyingly, reaction between $\mathbf{1}$ and equimolar amount of $\mathrm{Me}_{3} \mathrm{SiCN}$ yields the desired iron monocyanide species (2), however if the reaction is carried out with excess $\mathrm{Me}_{3} \mathrm{SiCN}$ the formation of 4 is observed. (Scheme $\mathrm{S} 1$ )

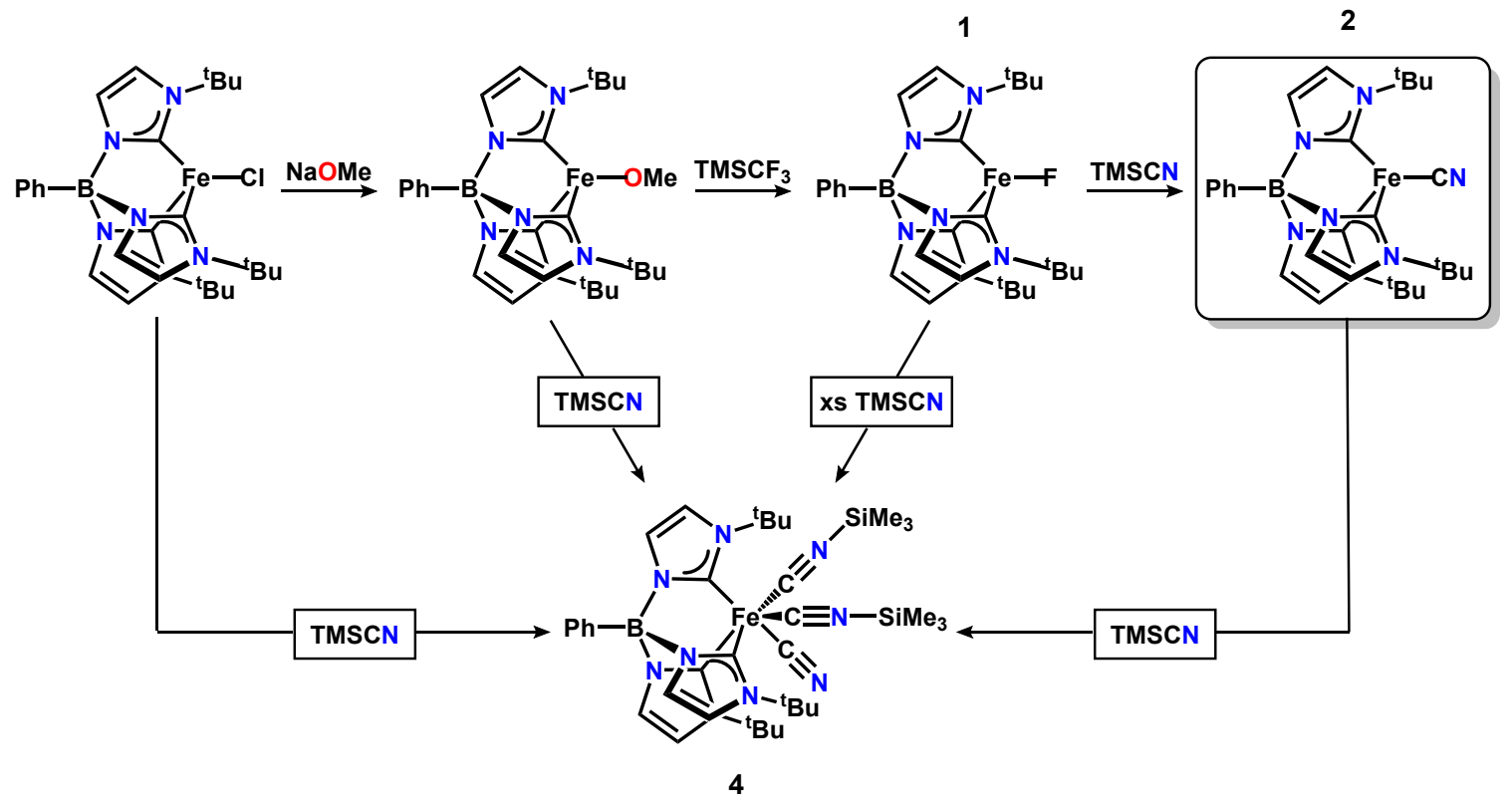

Scheme S1. Synthetic scheme of the pathways leading to the formation of 1, 2, and 4. 


\section{Supplementary Figures}

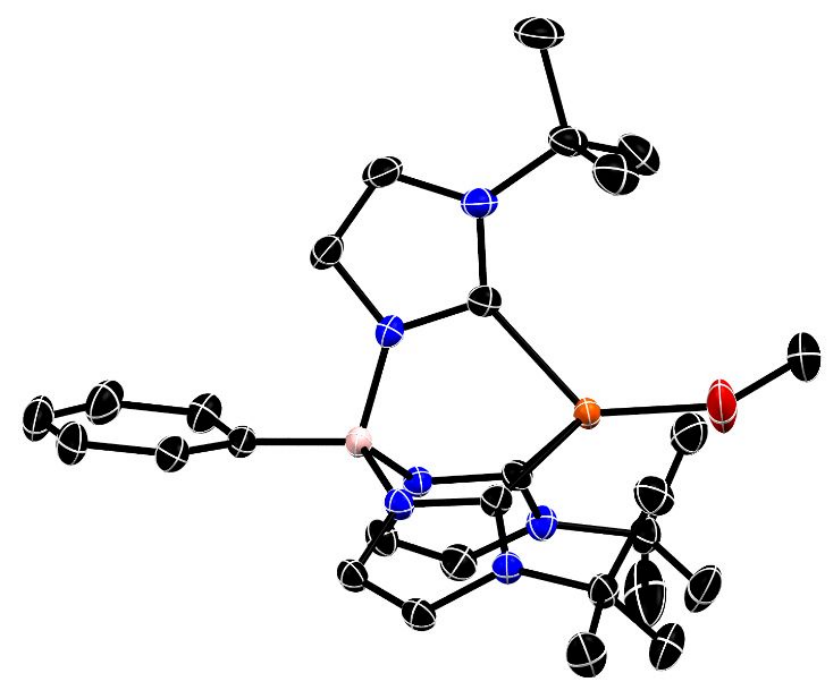

Figure S1. Molecular structure of $\mathbf{P h B}\left({ }^{\mathrm{t}} \mathrm{BuIm}\right)_{3} \mathrm{FeOCH}_{3}$. Color scheme: C, black; N, blue; B, pink; Fe, orange; $\mathrm{O}$, red. $\mathrm{H}$ atoms and solvent molecules have been omitted for clarity.
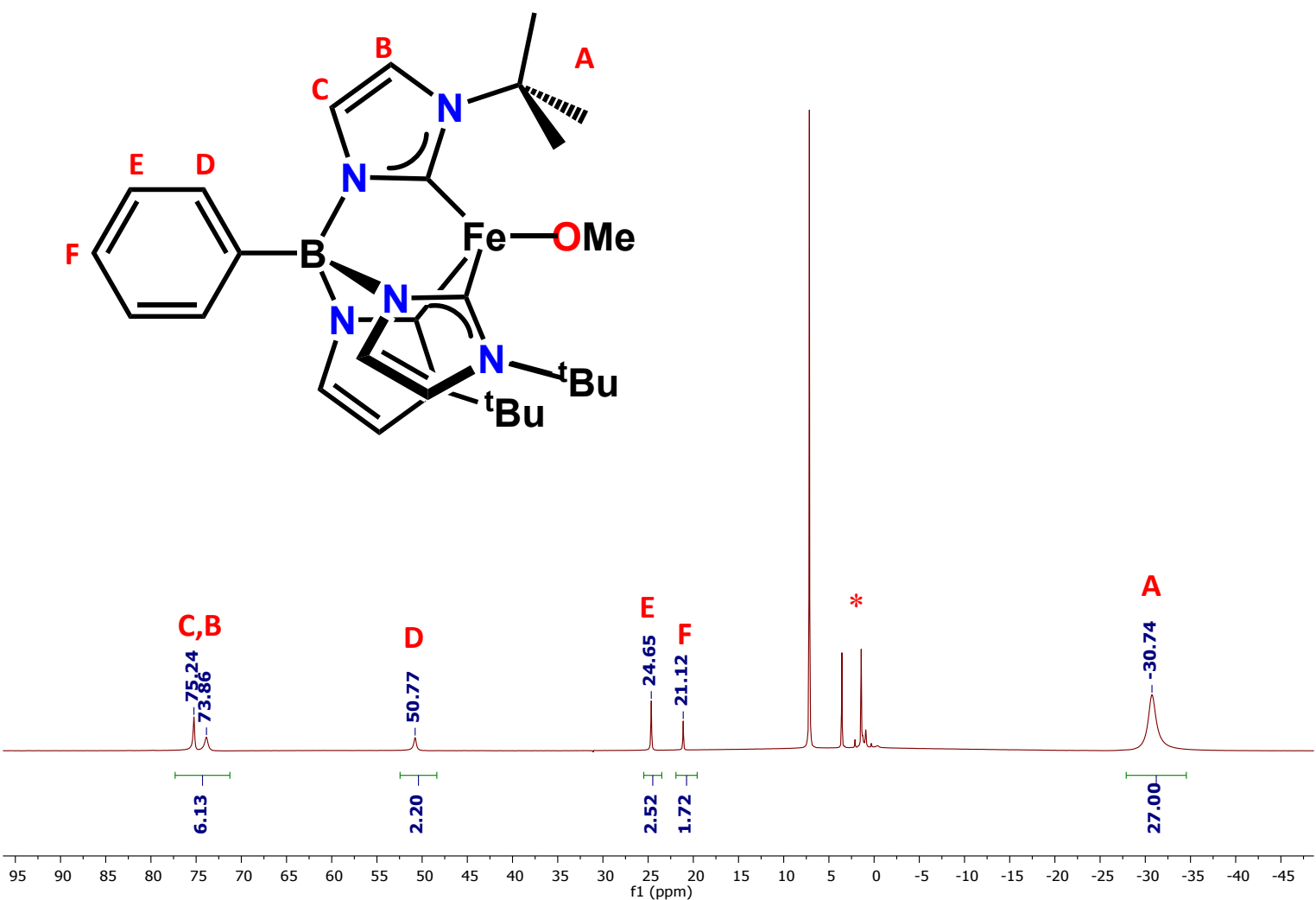

Figure S2. ${ }^{1} \mathrm{H}$ NMR spectrum of $\mathbf{P h B}\left({ }^{\mathrm{t}} \mathbf{B u I m}\right)_{3} \mathbf{F e O C H}_{3}\left(400 \mathrm{MHz}, \mathrm{C}_{6} \mathrm{D}_{6}, 25^{\circ} \mathrm{C}\right)$. The (*) denotes peaks from the residual THF solvent. 


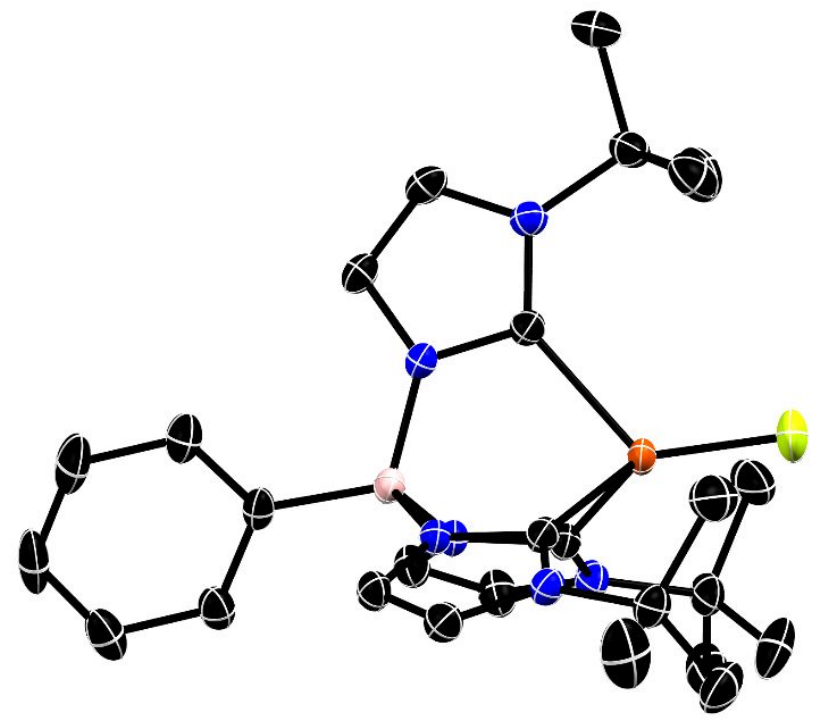

Figure S3. Molecular structure of 1. Color scheme: C, black; N, blue; B, pink; Fe, orange; F, yellow. $\mathrm{H}$ atoms and solvent molecules have been omitted for clarity.
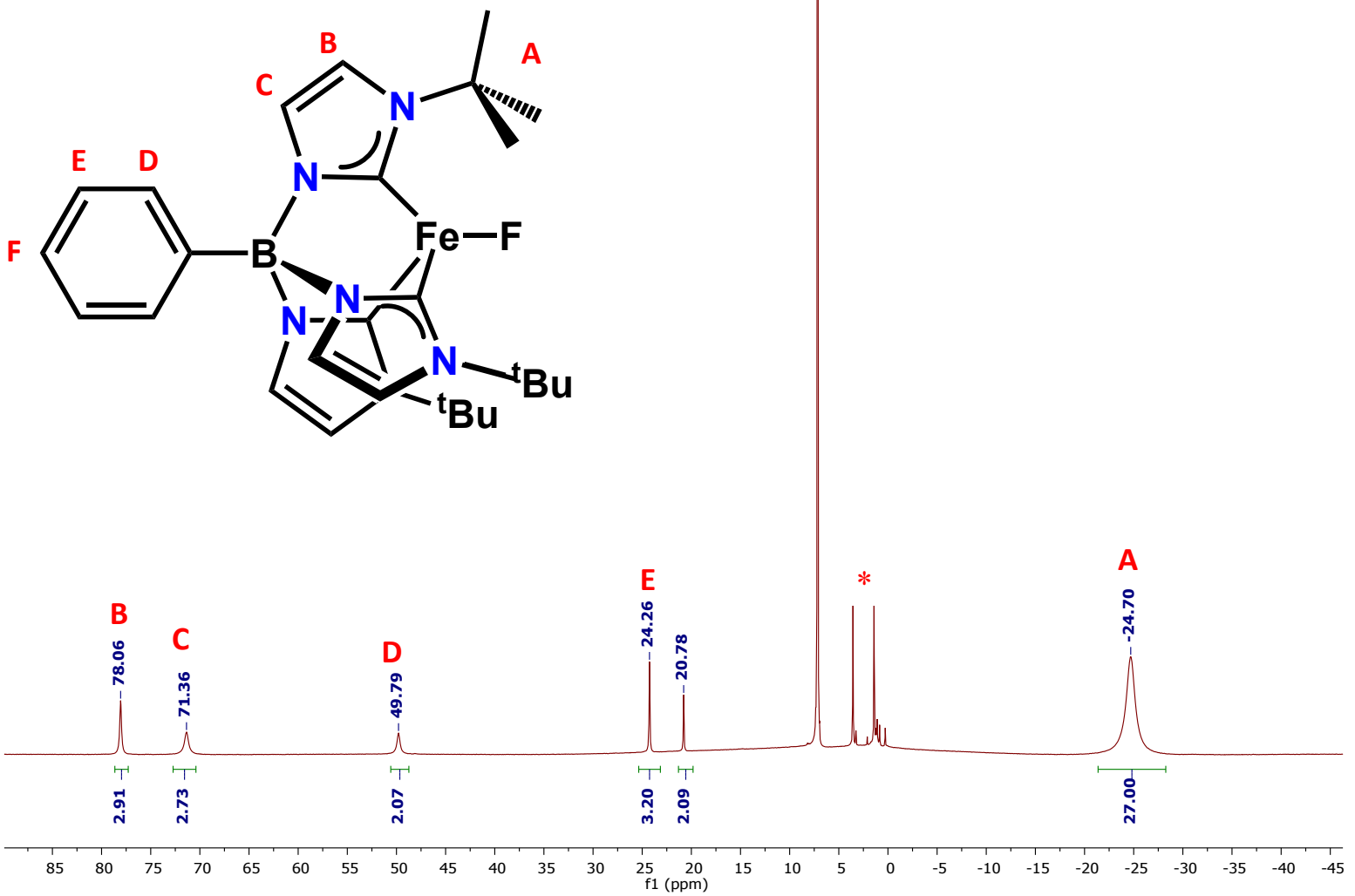

Figure S4. ${ }^{1} \mathrm{H}$ NMR spectrum of complex $1\left(400 \mathrm{MHz}, \mathrm{C}_{6} \mathrm{D}_{6}, 25^{\circ} \mathrm{C}\right)$. The $(*)$ denotes peaks from the residual THF solvent. 


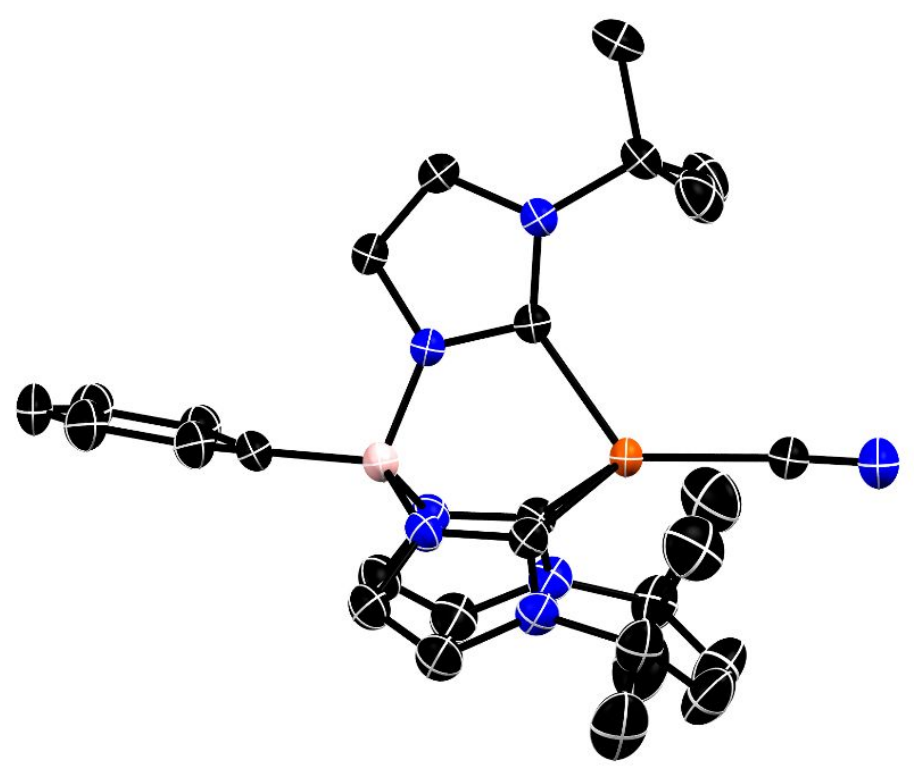

Figure S5. Molecular structure of 2. Color scheme: C, black; N, blue; B, pink; Fe, orange. H atoms and solvent molecules have been omitted for clarity.
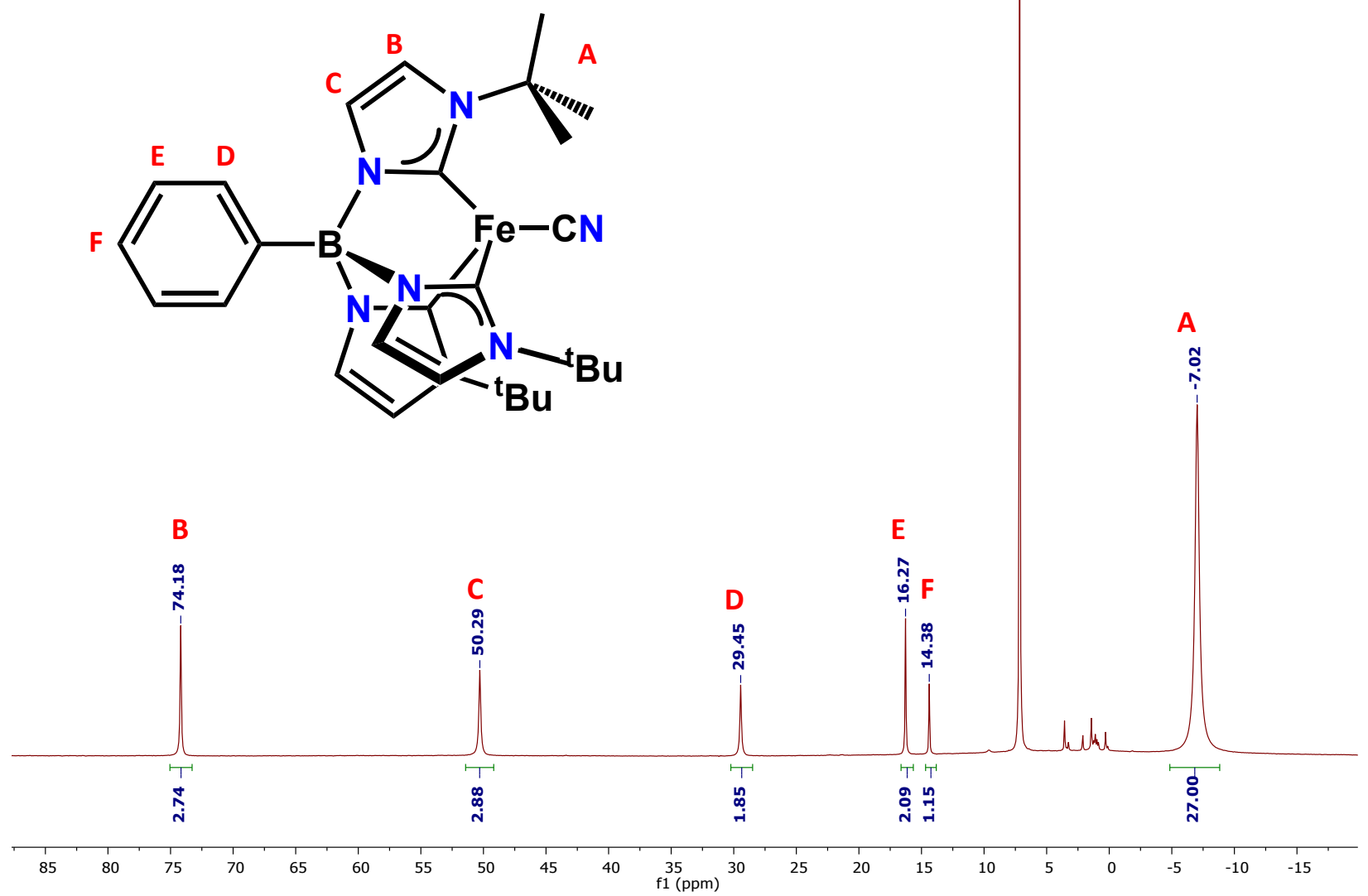

Figure S6. ${ }^{1} \mathrm{H}$ NMR spectrum of complex $2\left(400 \mathrm{MHz}, \mathrm{C}_{6} \mathrm{D}_{6}, 25^{\circ} \mathrm{C}\right)$. 


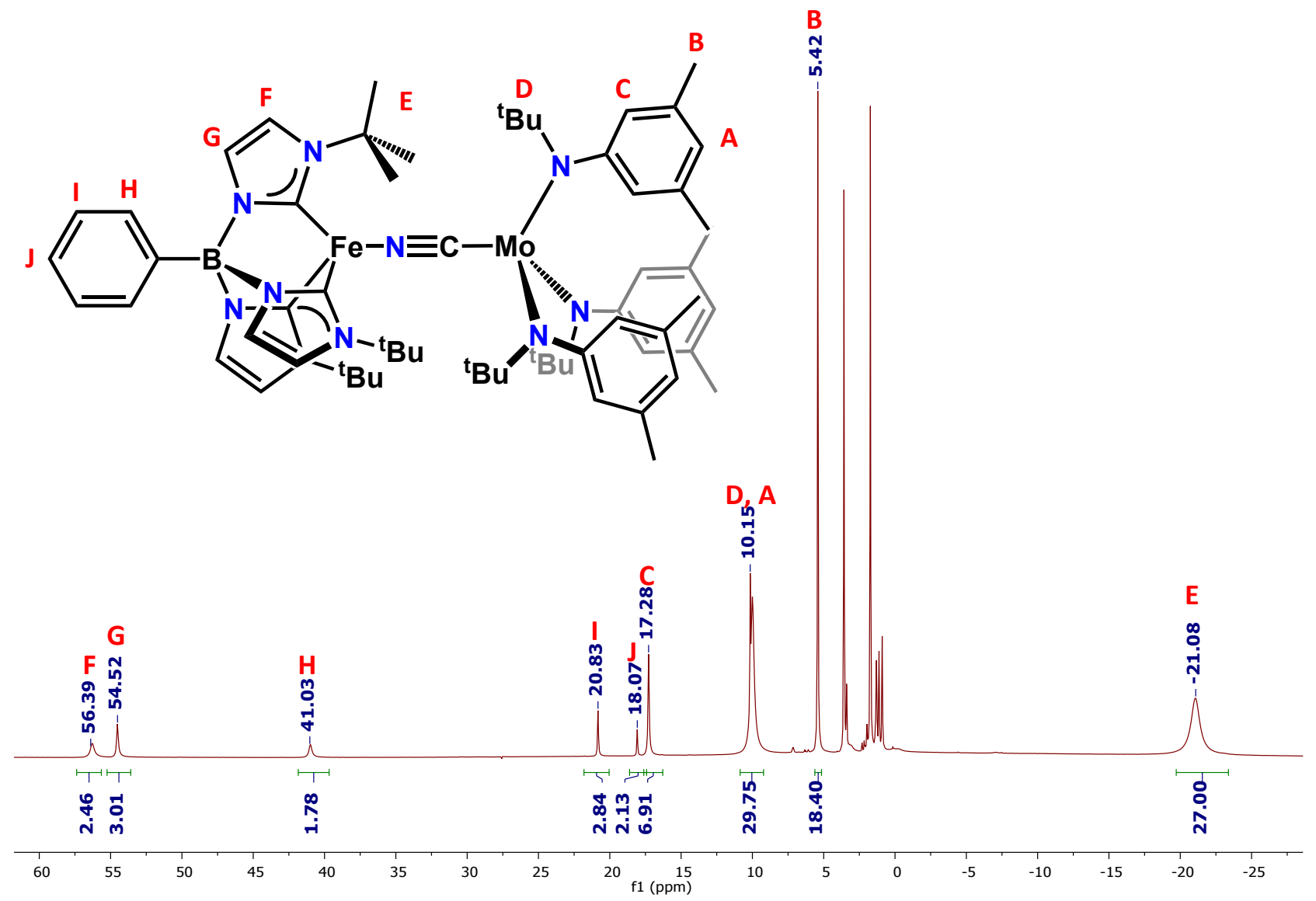

Figure S7. ${ }^{1} \mathrm{H}$ NMR spectrum of complex $3\left(400 \mathrm{MHz}, \mathrm{THF}-d_{8}, 25^{\circ} \mathrm{C}\right)$.

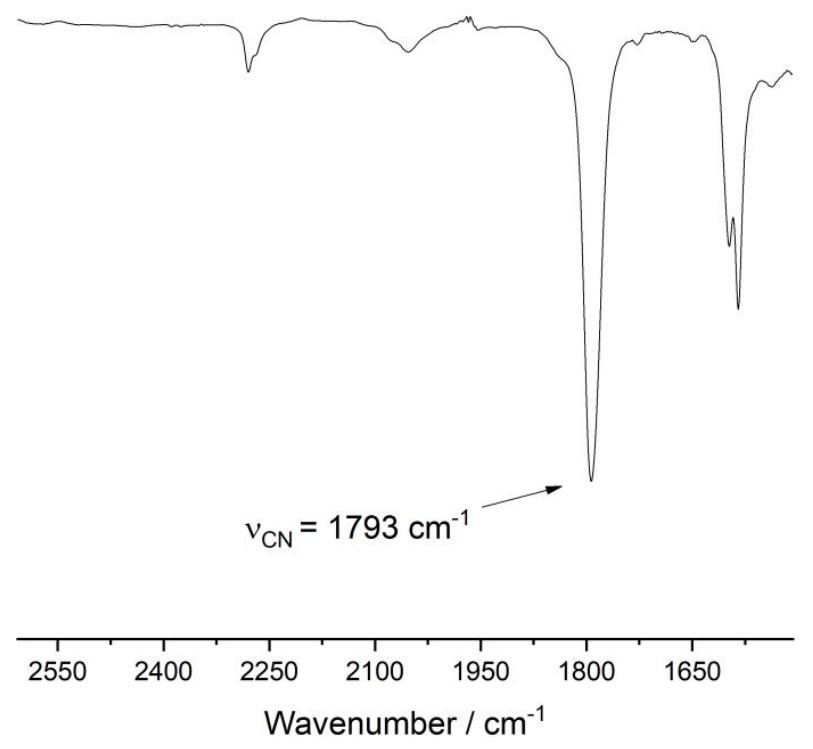

Figure S8. IR spectrum of $\mathbf{3}$ collected in THF at $25^{\circ} \mathrm{C}$. 


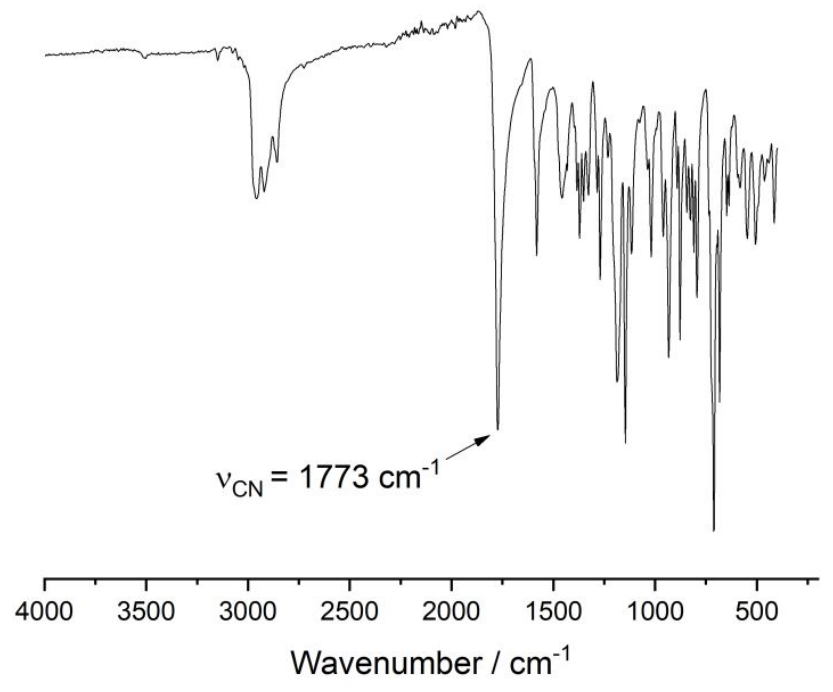

Figure S9. Solid state IR spectrum of $3(\mathrm{KBr})$ at $25^{\circ} \mathrm{C}$. 


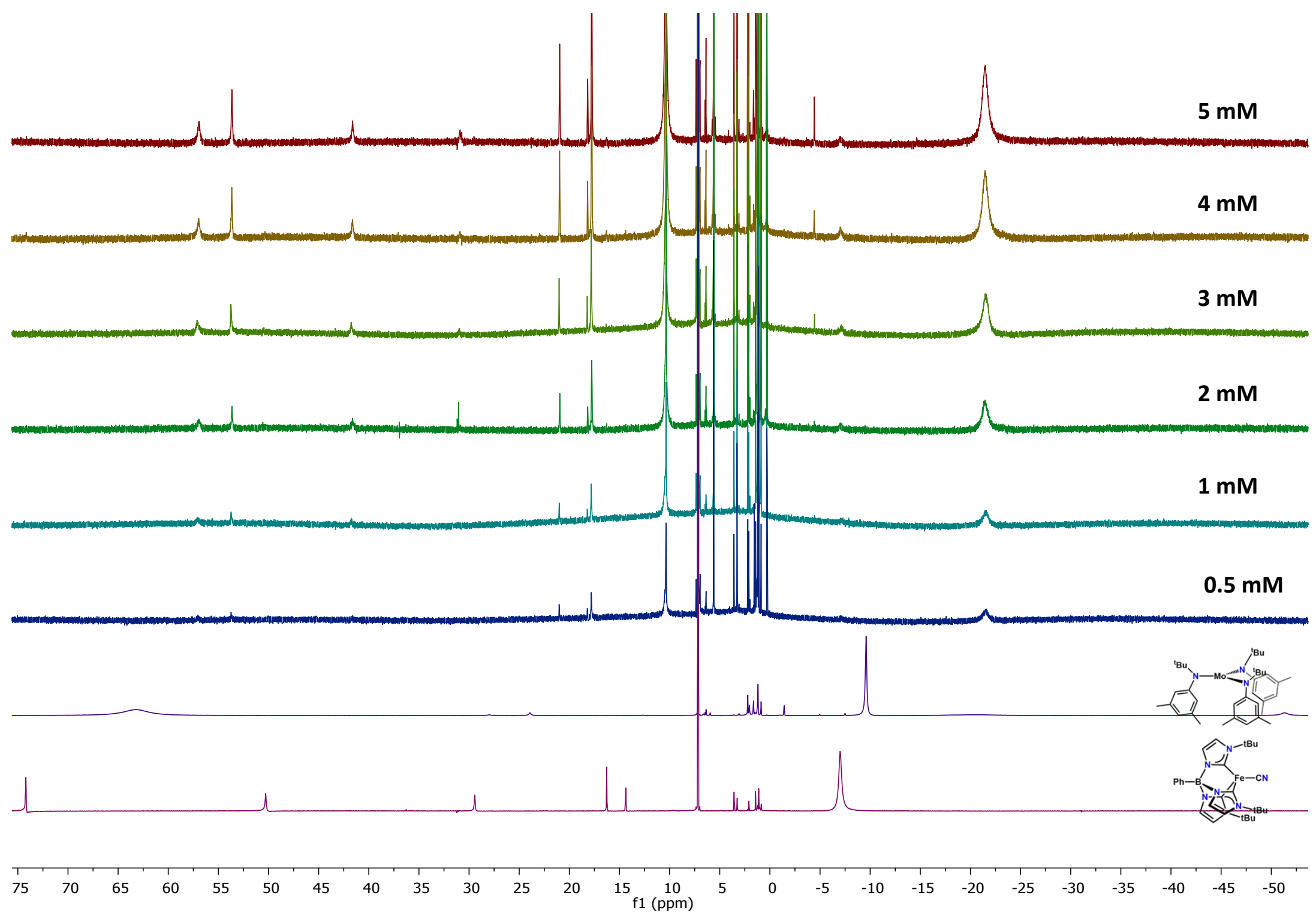

Figure S10. Variable-concentration ${ }^{1} \mathrm{H}$ NMR spectra for complex 3 in $\mathrm{C}_{6} \mathrm{D}_{6}$ at $25^{\circ} \mathrm{C}$. Spectra of $\mathrm{Mo}\left(\mathrm{N}^{\mathrm{t}} \mathrm{BuAr}\right)_{3}$ and 2 are shown for reference. 


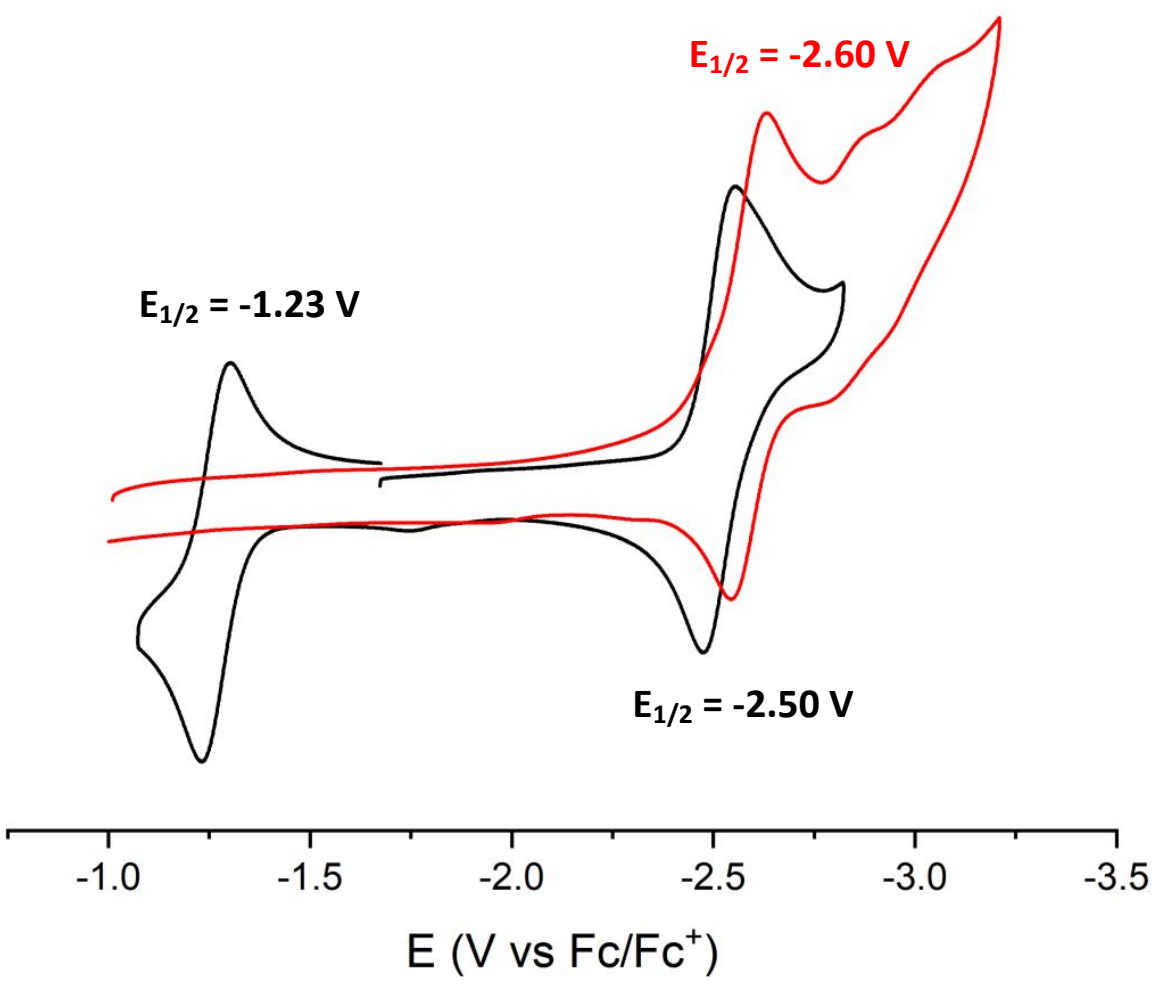

Figure S11. Overlaid cyclic voltammograms of $\mathbf{3}$ (black trace) and $\mathbf{2}$ (red trace) in THF with 0.4 $\mathrm{M}^{\mathrm{t}} \mathrm{Bu}_{4} \mathrm{NPF}_{6}$ as supporting electrolyte.

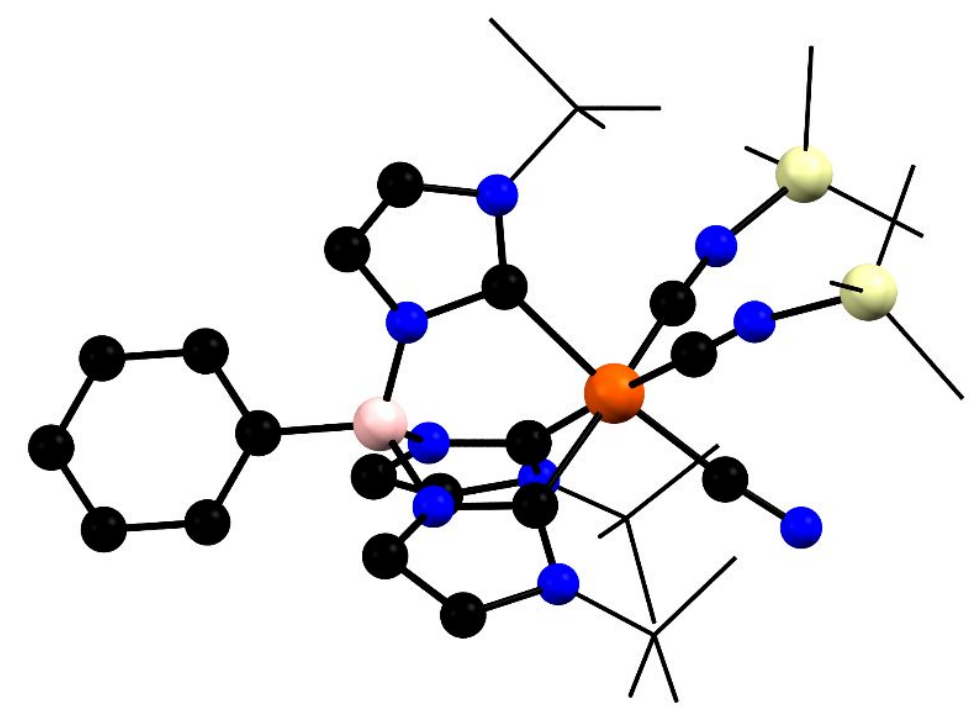

Figure S12. Ball and stick diagram showing the connectivity of 4. Color scheme: C, black; N, blue; $\mathrm{B}$, pink; Fe, orange; $\mathrm{Si}$, pale yellow. The ${ }^{\mathrm{B}} \mathrm{Bu}$ and Me groups are shown with wireframe representation for clarity. 


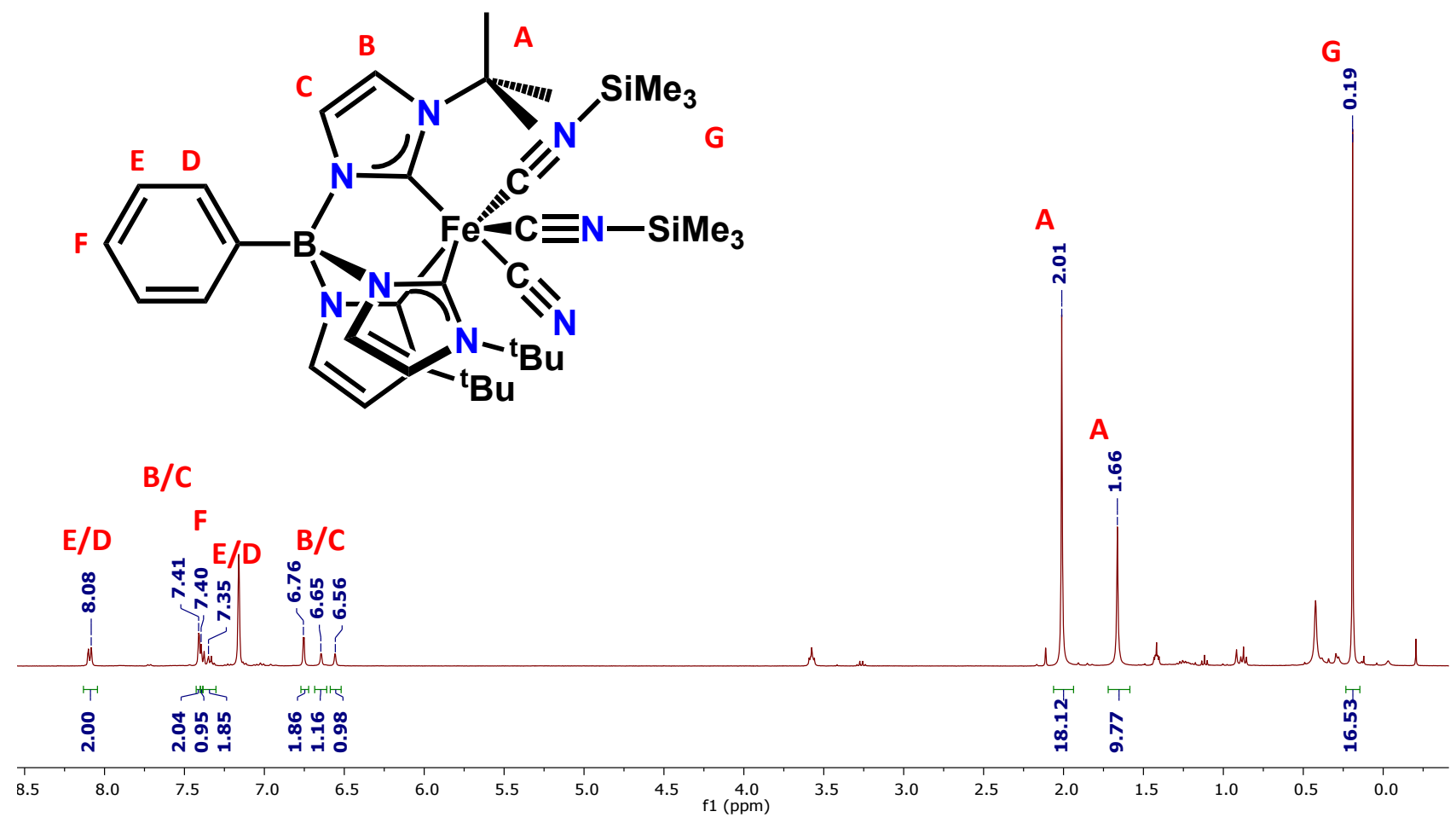

Figure S13. ${ }^{1} \mathrm{H}$ NMR spectrum of complex $4\left(400 \mathrm{MHz}, \mathrm{C}_{6} \mathrm{D}_{6}, 25^{\circ} \mathrm{C}\right)$. 


\section{Mössbauer Spectroscopy}

Zero-field ${ }^{57} \mathrm{Fe}$ Mössbauer spectra for $\mathbf{2}$ and $\mathbf{3}$ were collected with a constant acceleration spectrometer and a ${ }^{57} \mathrm{Co} / \mathrm{Rh}$ source over a $6 \mathrm{~mm} \mathrm{~s}^{-1}$ window. The spectrum for 2 was collected at $80 \mathrm{~K}$ and spectra for 3 were collected at 80 and $200 \mathrm{~K}$. Prior to the measurements, the spectrometer was calibrated at $295 \mathrm{~K}$ with a $30 \mu \mathrm{m}$-thick $\alpha$-Fe foil. Samples were prepared in a dry $\mathrm{N}_{2}$-filled glovebox. A typical sample contained $56 \mathrm{mg}$ of $2\left(5.8 \mathrm{mg}\right.$ of natural $\left.\mathrm{Fe} / \mathrm{cm}^{2}\right)$ or $80 \mathrm{mg}$ of $3(3.8$ $\mathrm{mg}$ of natural $\mathrm{Fe} / \mathrm{cm}^{2}$ ) and was prepared by adding solid material to a circular polyethylene holder of $1 \mathrm{~cm}^{2}$ area and squeezing another holder with a slightly smaller diameter that had been covered with deoxygenated Paratone-N oil into the previous sample holder to completely encapsulate the solid sample. The sample was frozen in liquid nitrogen prior to handling in air. Collected spectra were analyzed using the WMOSS Mössbauer Spectral Analysis Software (www.wmoss.org). Isomer shifts are reported relative to the centroid of the Fe metal spectrum recorded at $295 \mathrm{~K}$. The Mössbauer spectra were fit with Lorentzian doublets and parameter errors were estimated by Monte Carlo simulations. 


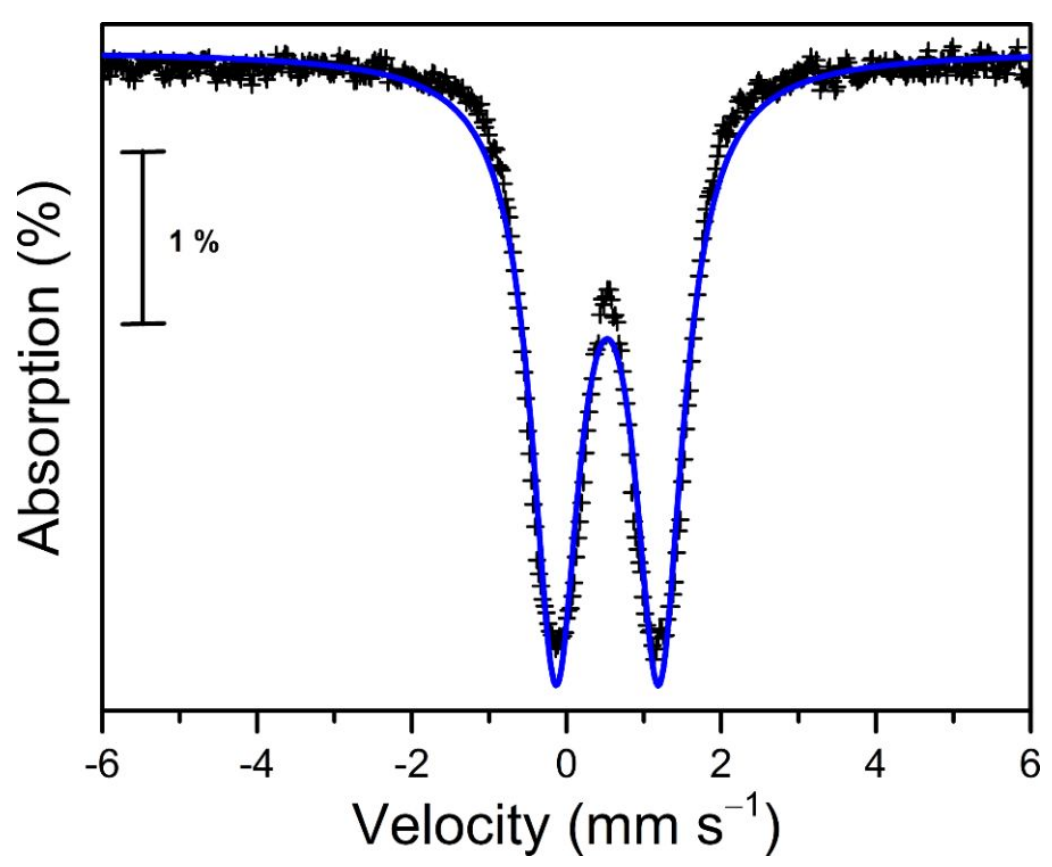

Figure S14. Mössbauer spectrum of 2 measured at $80 \mathrm{~K}$. Black crosses represent experimental data and the blue line corresponds to a fit of the data providing the following parameters: $\delta=$ $0.527(2) \mathrm{mm} \mathrm{s}^{-1} ; \Delta E_{\mathrm{Q}}=1.335(3) \mathrm{mm} \mathrm{s}^{-1}$.

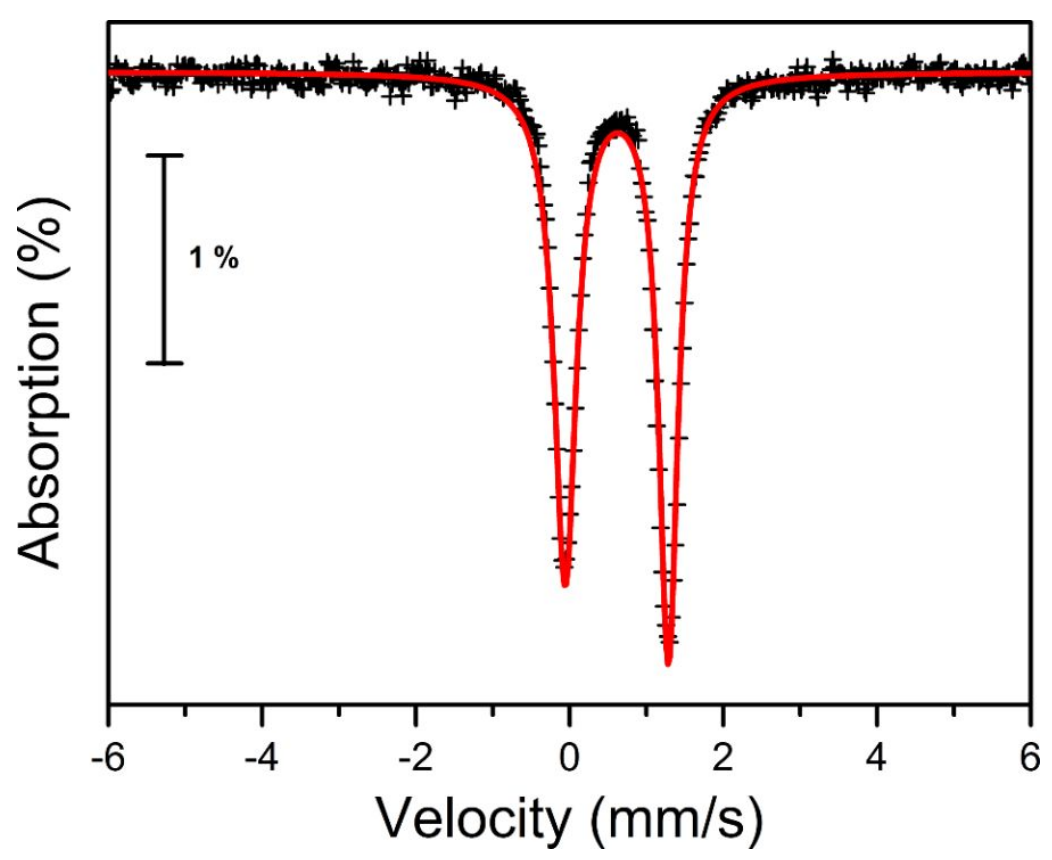

Figure S15. Mössbauer spectrum of $\mathbf{3}$ measured at $200 \mathrm{~K}$. Black crosses represent experimental data and the red line corresponds to a fit of the data providing the following parameters: $\delta=$ $0.614(1) \mathrm{mm} \mathrm{s}^{-1} ; \Delta E_{\mathrm{Q}}=1.345(2) \mathrm{mm} \mathrm{s}^{-1}$. 


\section{X-ray Photoelectron Spectroscopy (XPS)}

The oxidation state of $\mathrm{Fe}$ in the bimetallic compound $\mathbf{3}$ is assigned as being +2 , since the binding energies (BE) for $\mathrm{Fe} 2 \mathrm{p}_{3 / 2}$ line $(709.62 \mathrm{eV})$ and shake-up satellite $(714.05 \mathrm{eV})$ are consistent with those of the reference compound $\left(\mathrm{PhB}(\mathrm{MesIm})_{3} \mathrm{FeCl}\right){ }^{5}$ This oxidation state assignment is also consistent with the assignment from Mössbauer spectroscopy.

A small library of Mo complexes in different oxidation states was constructed to investigate the Mo oxidation state in the bimetallic compound 3 (Figure $\mathrm{S} 17) . \mathrm{Mo}^{\mathrm{IV}}(\mathrm{I})\left(\mathrm{N}^{\mathrm{t}} \mathrm{BuAr}\right)_{3}(\mathrm{MoI}){ }^{6}$ $\mathrm{Mo}^{\mathrm{V}}(\mathrm{O})\left(\mathrm{N}^{\mathrm{t}} \mathrm{BuAr}\right)_{3}(\mathrm{MoO}),{ }^{7} \mathrm{Mo}^{\mathrm{VI}}(\mathrm{N})\left(\mathrm{N}^{\mathrm{t}} \mathrm{BuAr}\right)_{3}(\mathrm{MoN}),{ }^{2}$ and $\left[\mathrm{CH}_{3} \mathrm{NMo}^{\mathrm{VI}}\left(\mathrm{N}^{\mathrm{t}} \mathrm{BuAr}\right)_{3}\right] \mathrm{I}\left(\mathrm{MoNCH}_{3}\right)^{8}$ were prepared as reference complexes. There is a clear trend in increased $\mathrm{BE}$ for $\mathrm{Mo}^{\mathrm{IV}} \mathrm{I}(229.26$ $\mathrm{eV}), \mathrm{Mo}^{\mathrm{V}} \mathrm{O}(230.62 \mathrm{eV})$, and $3(231.62 \mathrm{eV})$, suggesting an oxidation state higher than +5 for complex 3. However, $\mathrm{Mo}^{\mathrm{VI}} \mathrm{N}$ has a lower $\mathrm{BE}(230.19 \mathrm{eV})$ than $\mathrm{Mo}^{\mathrm{V}} \mathrm{O}(230.62 \mathrm{eV})$, despite the higher oxidation state. This is likely due to the differences in covalency for the oxo and nitride complexes, which is further supported by the XPS data of the imido $\mathrm{MoNCH}_{3}$. Both $\mathrm{MoN}$ and $\mathrm{MoNCH}_{3}$ have the same oxidation state $(+6)$ but different degrees of covalency. Consistent with this hypothesis, $\mathrm{BE}$ for $\mathrm{MoNCH}_{3}(231.37 \mathrm{eV})$ is higher than for MoN. A complete consideration of these data leads us to conclude that the oxidation state of Mo in $\mathbf{3}$ cannot be definitively determined by XPS, however the data do strongly support Mo being in a higher oxidation state in complex 3 than in the starting material $\left(\mathrm{Mo}\left(\mathrm{N}^{\mathrm{t} B u A r}\right)_{3}\right)$. 


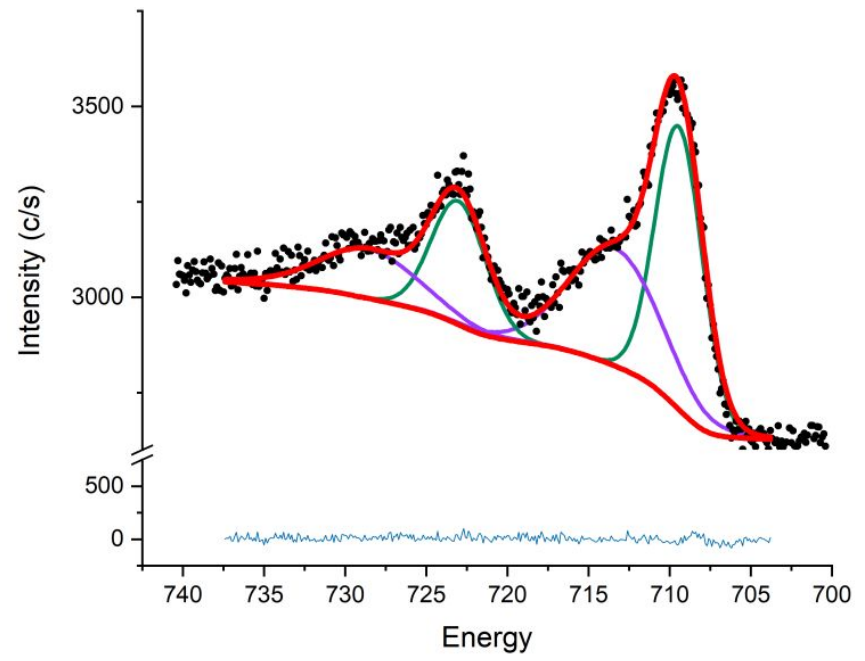

Figure S16. High resolution Fe 2p spectra of $\mathrm{PhB}\left({ }^{\mathrm{t}} \mathrm{BuIm}\right)_{3} \mathrm{FeNCMo}\left(\mathrm{N}^{t} \mathrm{Bu}\right] \mathrm{Ar}_{3}$ (3). Black line represents experimental data, red line shows generated fit, the green line represents $\mathrm{Fe} 2 \mathrm{p}_{3 / 2}$ and $\mathrm{Fe} 2 \mathrm{p}_{1 / 2}$, and the purple line represents shake-up satellites.

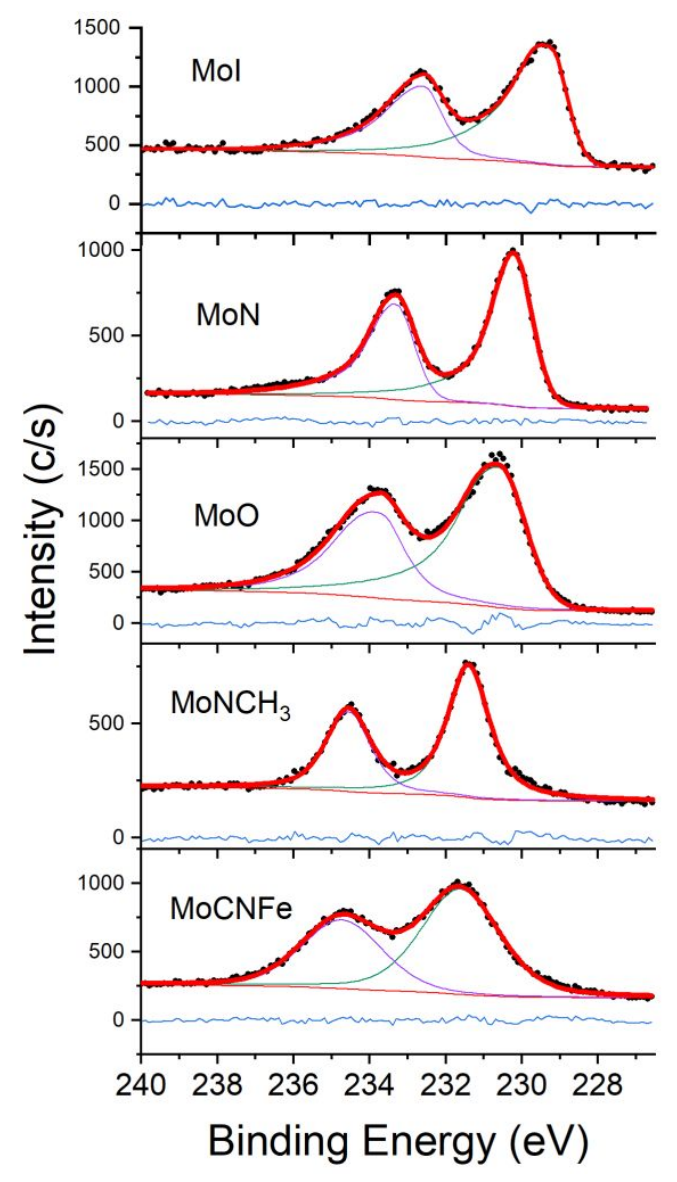

Figure S17. Stacked high resolution Mo 3d spectra of 3 (bottom) and $\mathrm{LMo}\left(\mathrm{N}^{\mathrm{t} B u A r}\right)_{3}(\mathrm{~L}=\mathrm{I}, \mathrm{N}$, $\mathrm{O}, \mathrm{NCH} 3)$. Black line represents experimental data, red line shows generated fit, the green line represents Mo $3 \mathrm{~d}_{5 / 2}$ and the purple line represents Mo $3 \mathrm{~d}_{3 / 2}$. 


\section{Magnetic Measurements}

Magnetic measurements of $\mathbf{3}$ were performed on finely ground microcrystalline samples sealed in a polyethylene bag under an atmosphere of dinitrogen ( $\mathrm{dc}$ field measurements) or restrained in an eicosane matrix in a quartz tube under a dry $\mathrm{N}_{2}$ atmosphere, attached to a sealable hose adapter, and flame-sealed under vacuum on a Schlenk manifold (ac field measurements). All data were collected using a Quantum Design MPMS-XL SQUID magnetometer. Dc susceptibility data were collected from 2 to $350 \mathrm{~K}$ under applied dc fields of 0.5 and $1 \mathrm{~T}$. Low temperature magnetization data were collected between 2 and $10 \mathrm{~K}$ under applied dc fields ranging from 0 to $+7 \mathrm{~T}$. Ac magnetic susceptibility data were collected between 1.8 and $10.2 \mathrm{~K}$ under an ac field of 4 Oe, oscillating at frequencies in the range $1-1488 \mathrm{~Hz}$, and dc fields of 0 and $1200 \mathrm{Oe}$. Ac magnetic susceptibility data were used to construct Cole-Cole plots, which were then fit using a generalized Debye model ${ }^{9-11}$ in the temperature range $5.8-8.6 \mathrm{~K}$ to estimate relaxation times. Prior to full characterization measurements, variable-dc field magnetization data were collected from 0 to +3 $\mathrm{T}$ at $100 \mathrm{~K}$ to ensure the absence of curvature in $M$ vs $H$ curves associated with significant ferromagnetic impurities. All data were corrected for diamagnetic contributions from the sample holder (polyethylene bag for dc measurements and eicosane matrix for ac measurements) and for the core diamagnetism of the compound (estimated using Pascal's constants). ${ }^{12}$ Specifically, for dc measurements, the diamagnetic correction for the polyethylene bag sample holder was estimated according to the following equation:

$$
M_{\text {bag }}=\left(\left(2.6673 \times 10^{-10}\right) / T-7.5049 \times 10^{-10}\right) \times H \times \mathrm{m}_{\text {bag }}(\text { Eq. S1 })
$$

In this equation, $M_{\mathrm{bag}}$ is the diamagnetic moment of the sample holder, $T$ is the temperature in Kelvin, $H$ is the magnetic field in Oe, and $\mathrm{m}_{\text {bag }}$ is the mass of the bag in $\mathrm{mg}$. This relationship was derived on our SQUID magnetometer by measuring the diamagnetism of a number of polyethylene 
bags of different masses. The temperature-dependent dc magnetic susceptibility data for $\mathbf{3}$ were modelled in the temperature range 40-350 K using the following spin Hamiltonian:

$$
\hat{H}=-2 J\left(\hat{S}_{\mathrm{Fe}} \cdot \hat{S}_{\mathrm{Mo}}\right)+g \mu_{\mathrm{B}} H\left(\hat{S}_{\mathrm{Fe}}+\hat{S}_{\mathrm{Mo}}\right)+D \hat{S}_{\mathrm{Fe}, \mathrm{z}}{ }^{2} \text { (Eq. S2) }
$$

In this Hamiltonian, the first term is the exchange coupling term, the second term denotes the Zeeman interaction and the last term is the axial zero-field interaction. The parameter $J$ is the exchange coupling constant, $\hat{S}_{\mathrm{M}}(\mathrm{M}=\mathrm{Fe}, \mathrm{Mo})$ is the metal ion spin angular momentum operator, $g$ is the isotropic electron spin $g$-factor $\left(g=g_{\mathrm{Fe}}=g_{\mathrm{Mo}}\right), \mu_{\mathrm{B}}$ is the Bohr magneton, $H$ is the applied magnetic field, $D$ is the axial zero-field splitting parameter and $\hat{S}_{\mathrm{Fe}, z}$ is the $z$ component of the $\mathrm{Fe}$ ion spin angular momentum operator. The best fits of the data gave values of $J=-118(2) \mathrm{cm}^{-1}, g$ $=2.3(1)$ and $D=-24(1) \mathrm{cm}^{-1}$, and $J=-122(2) \mathrm{cm}^{-1}, g=2.3(1)$ and $D=-22(1) \mathrm{cm}^{-1}$ for the data collected under an applied field of 0.5 and $1 \mathrm{~T}$, respectively. The error bars for the parameters obtained from these fits were estimated by evaluating the errors of the experiments. Specifically, the largest source of error is associated with mass errors for the sample (16.7-30.9 mg) and polyethylene bag (51.5-52.3 mg), which then affect the diamagnetic correction. When we assume $\pm 1 \mathrm{mg}$ error (which is about three-fold overestimation based on recent calibration of our balance) for either the sample or polyethylene bag, the error bars denoted above were obtained. Note, however, that using a spin-only Hamiltonian for this strongly-coupled dinuclear cyano-bridged system is only an approximation. The data could only be reliably modeled above $40 \mathrm{~K}$, owing possibly to contributions from spin-orbit coupling from the $4 \mathrm{~d}$ Mo center. Accordingly, we were unable to fit the low temperature magnetization data for $\mathbf{3}$ using the spin-only Hamiltonian provided in Eq. S2. The program MagProp within the NIST DAVE software suite was employed to simulate and fit all magnetic susceptibility and low-temperature magnetization data. ${ }^{13-14 \mathrm{~s}}$ 


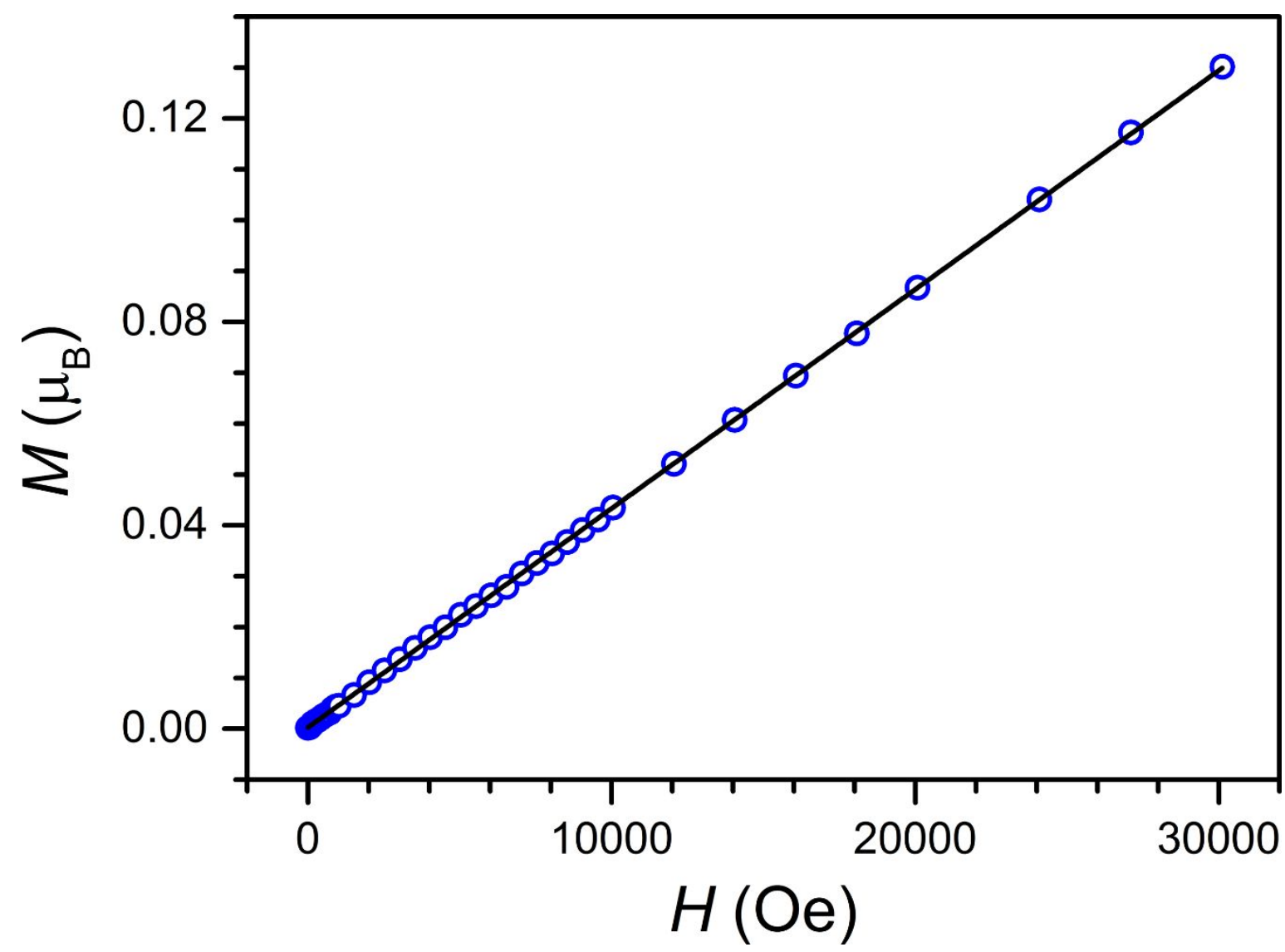

Figure S18. Variable-field dc magnetization data for 3 at $100 \mathrm{~K}$, collected for a sample prepared in a polyethylene bag. Blue circles represent experimental data and the black line indicates a linear fit of the data. 


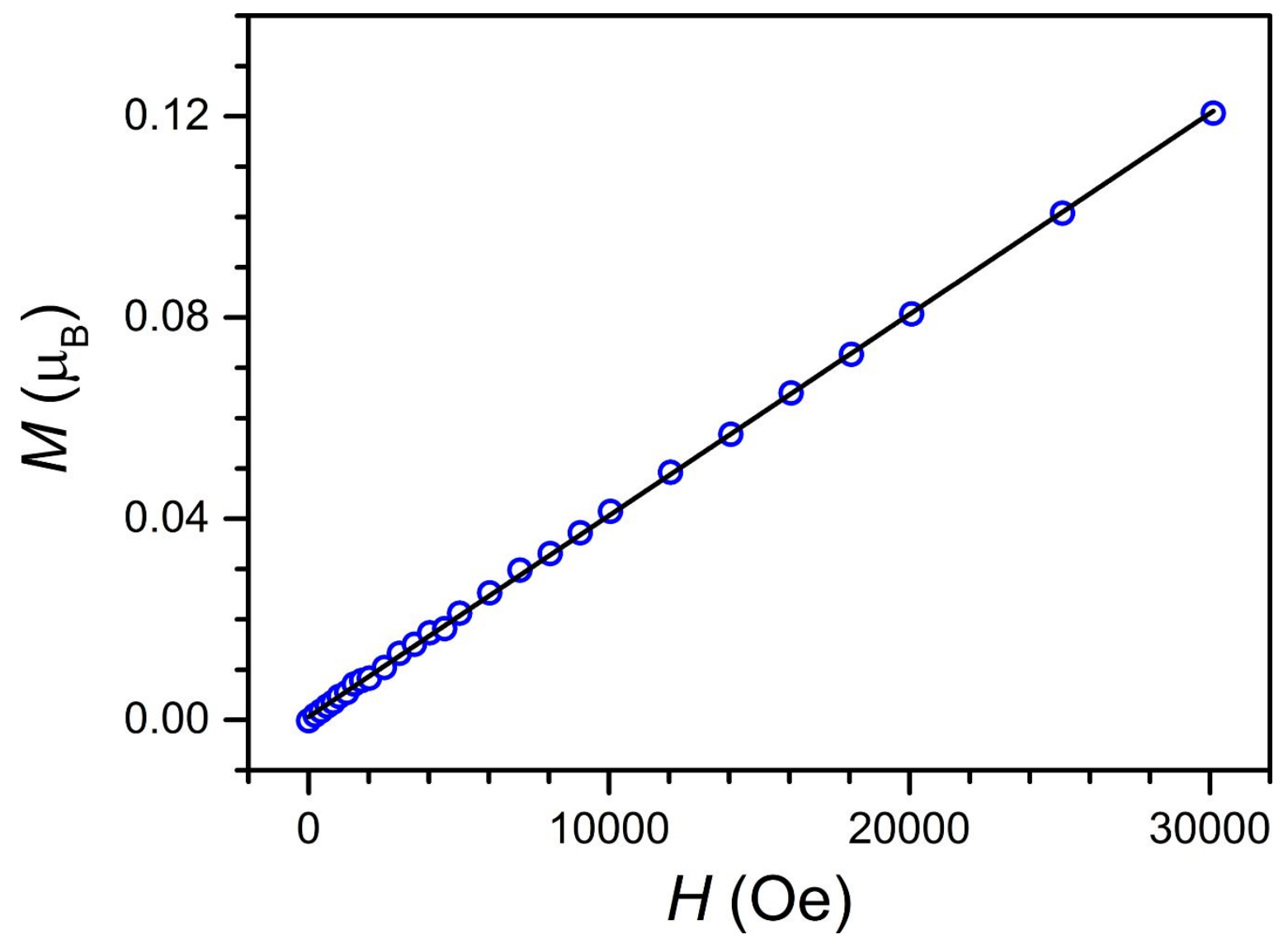

Figure S19. Variable-field dc magnetization data for 3 at $100 \mathrm{~K}$, collected for a sample prepared in an eicosane matrix in a quartz tube. Blue circles represent experimental data and the black line indicates a linear fit of the data. 


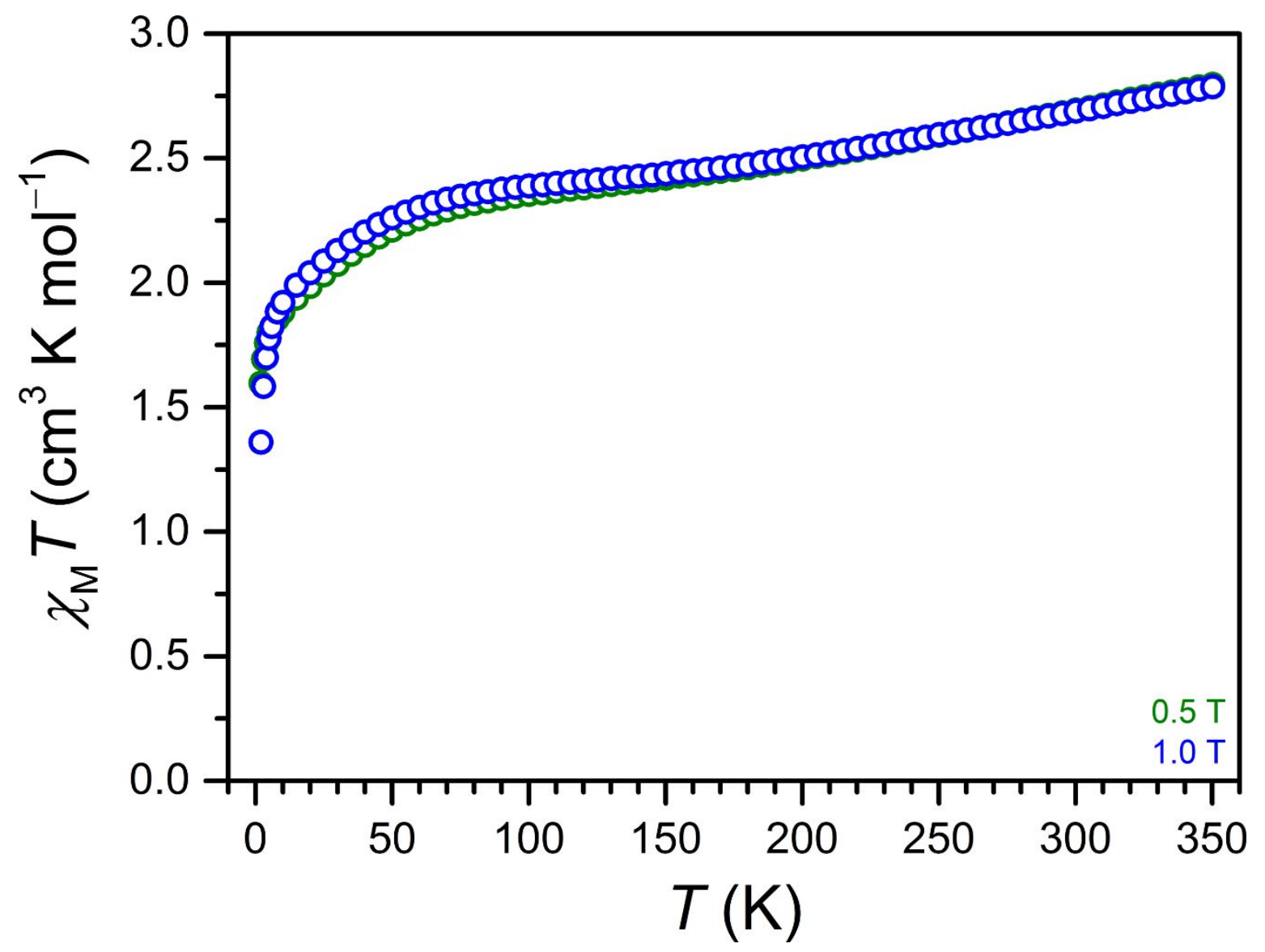

Figure S20. Variable-temperature dc magnetic susceptibility data for 3, collected at fields of 0.5 (green) and 1.0 (blue) T. Note the overlay of the data obtained at the two fields at high temperatures indicative of the absence of sample torquing. 


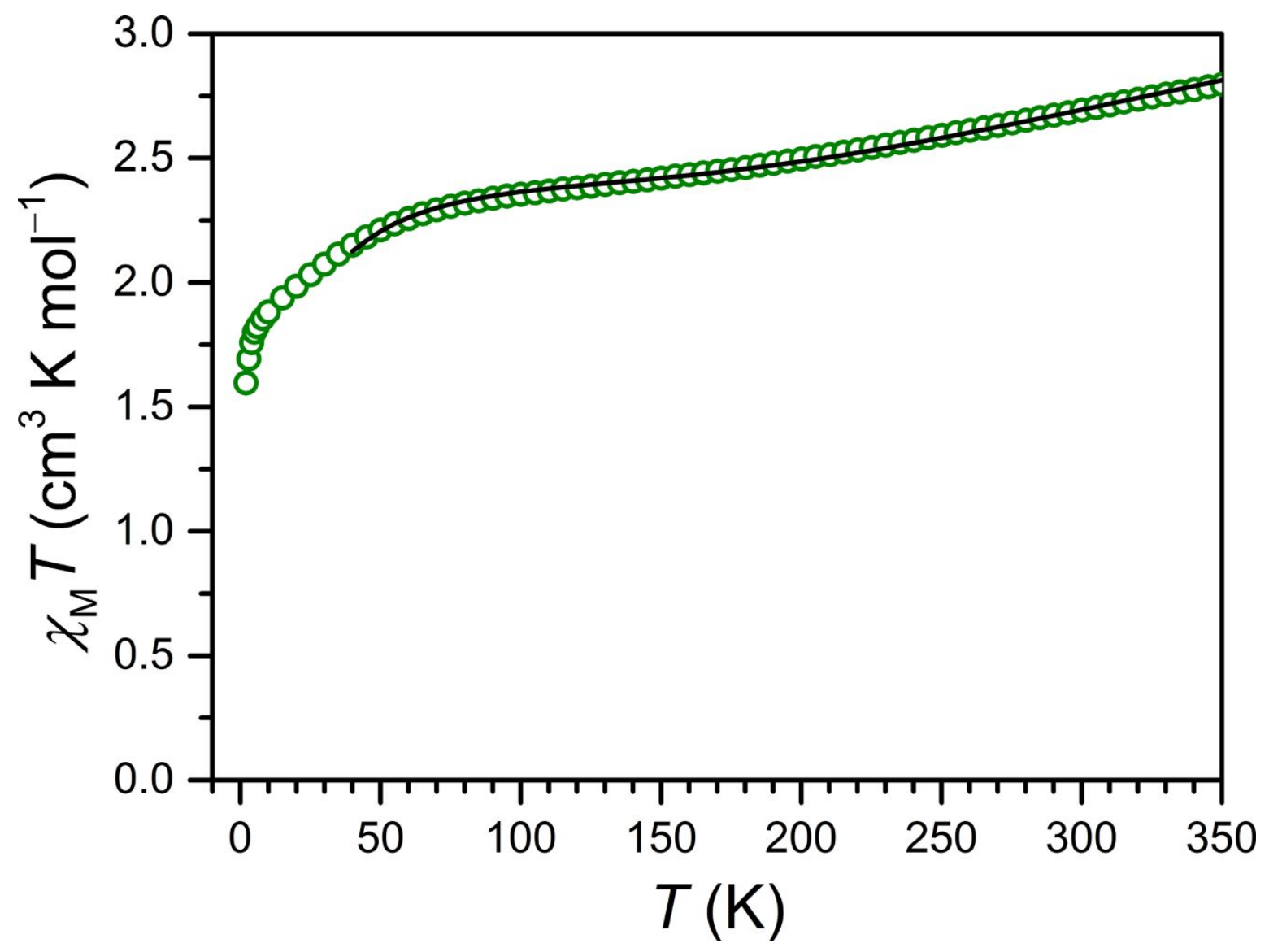

Figure S21. Variable-temperature dc magnetic susceptibility data for 3, collected at a field of $0.5 \mathrm{~T}$. Green circles represent experimental data and the black line indicates a fit of the data in the temperature range $50-350 \mathrm{~K}$ using the spin Hamiltonian provided in Eq. S1. The best fit of the data gave the following parameters: $J=-119 \mathrm{~cm}^{-1} ; g=2.28 ; D=-26 \mathrm{~cm}^{-1}$. 


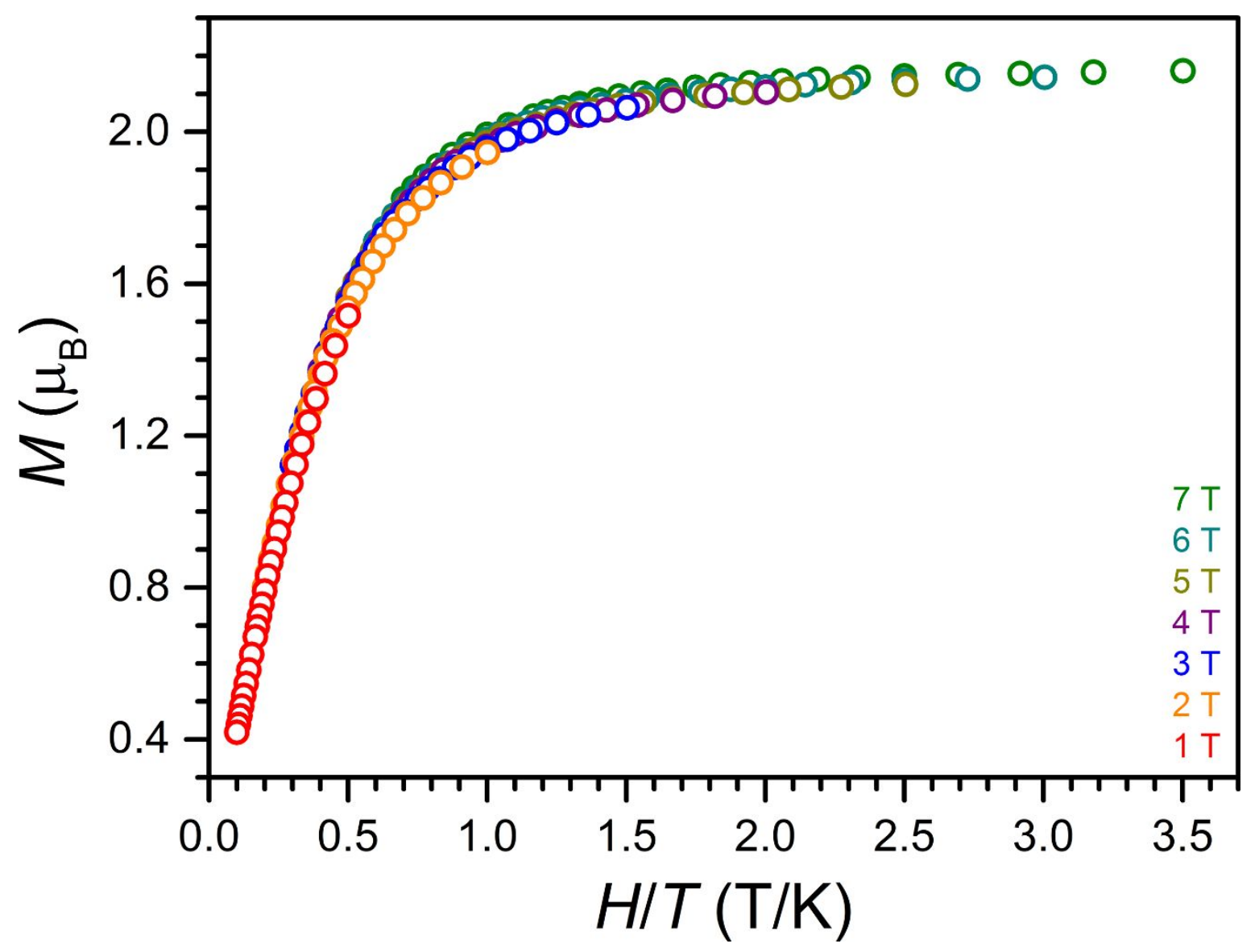

Figure S22. Low temperature magnetization data for 3, collected at selected dc fields (see legend). 


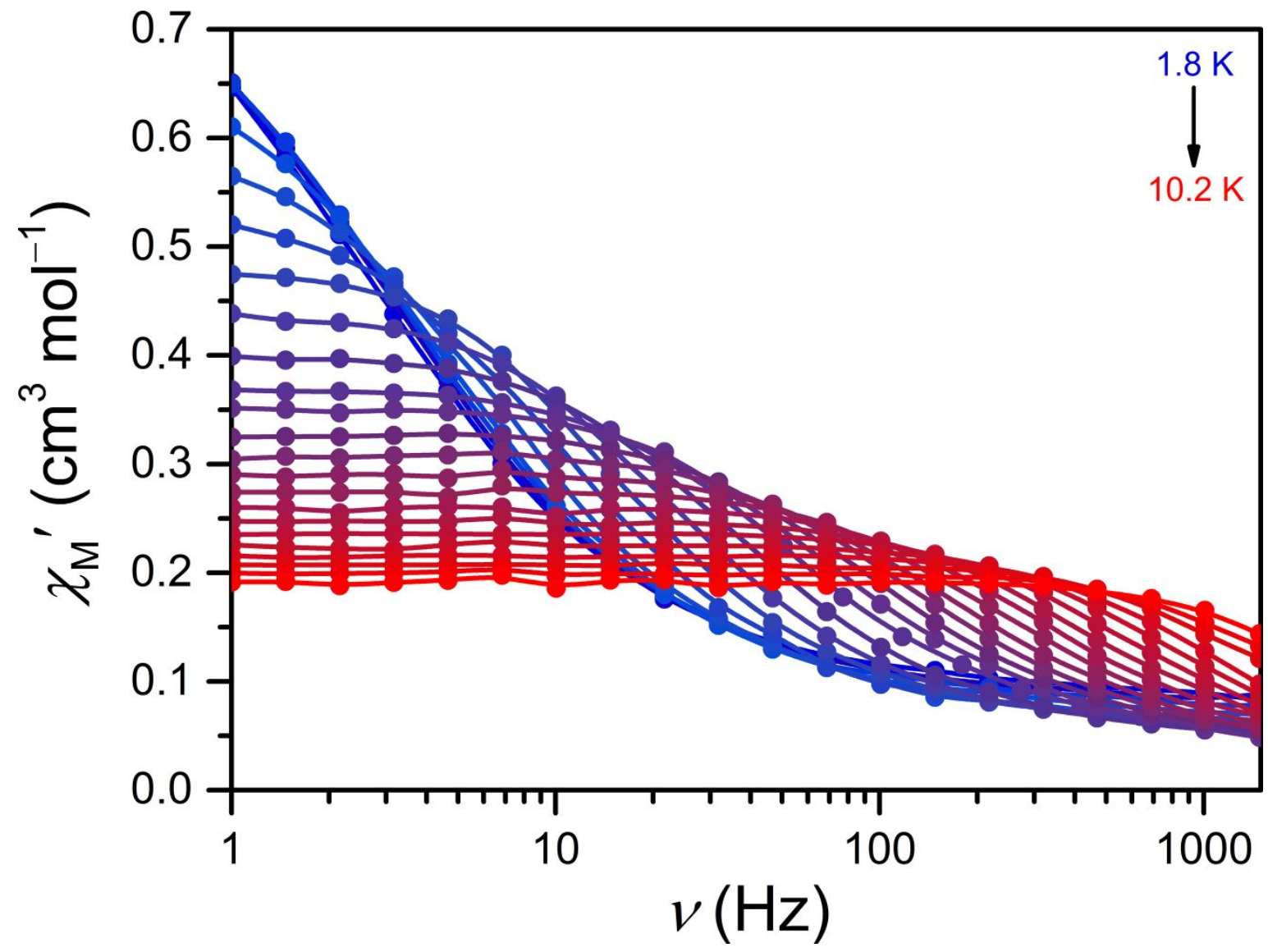

Figure S23. Plot of variable-frequency in-phase ac magnetic susceptibility data for $\mathbf{3}$ between 1.8 (dark blue) and 10.2 K (red), collected under an applied dc field of 1200 Oe. Note that the solid lines serve as a guide to the eye. 


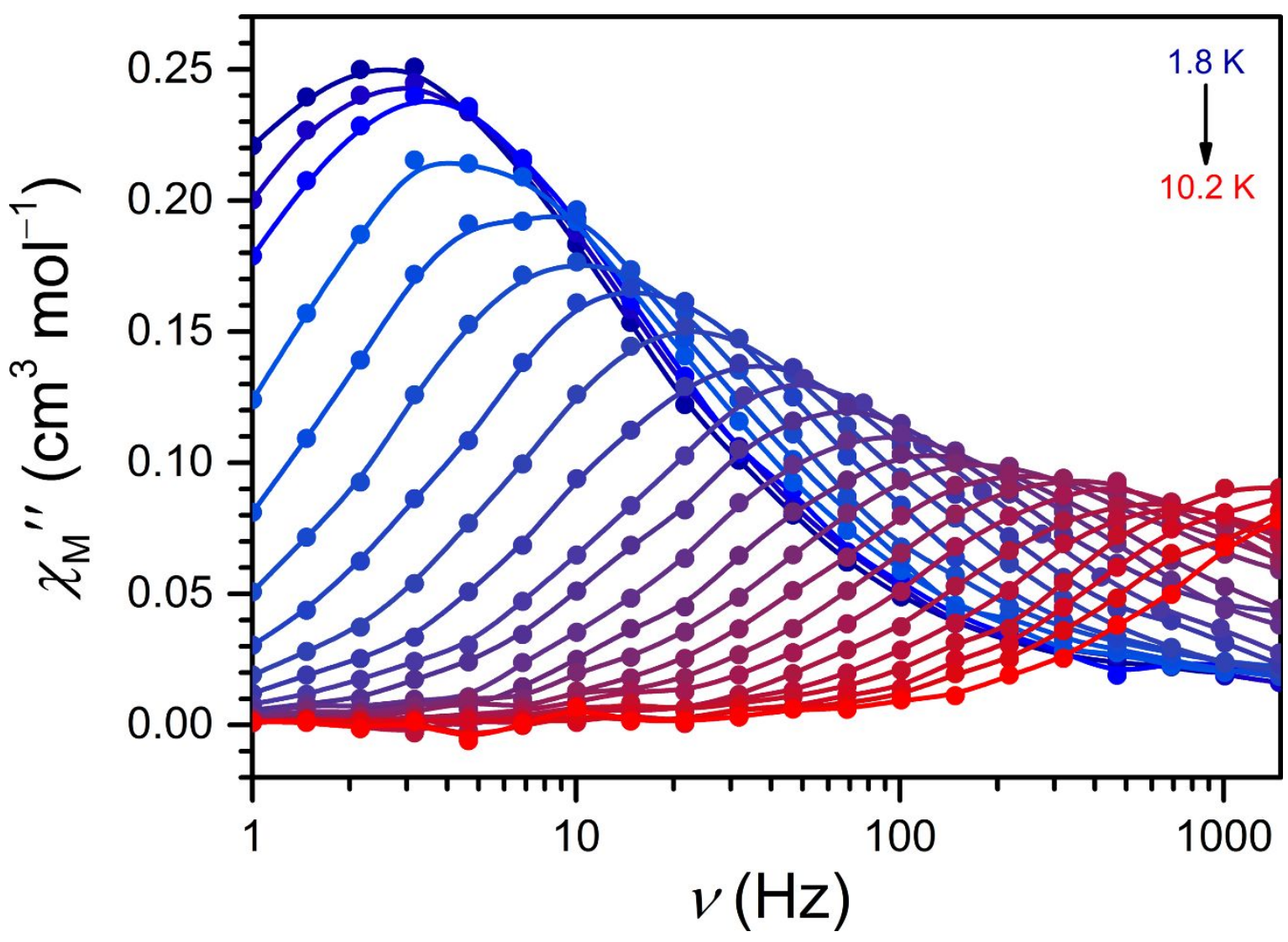

Figure S24. Plot of variable-frequency out-of-phase ac magnetic susceptibility data for $\mathbf{3}$ between 1.8 (dark blue) and 10.2 K (red), collected under an applied dc field of 1200 Oe. Note that the solid lines serve as a guide to the eye. 


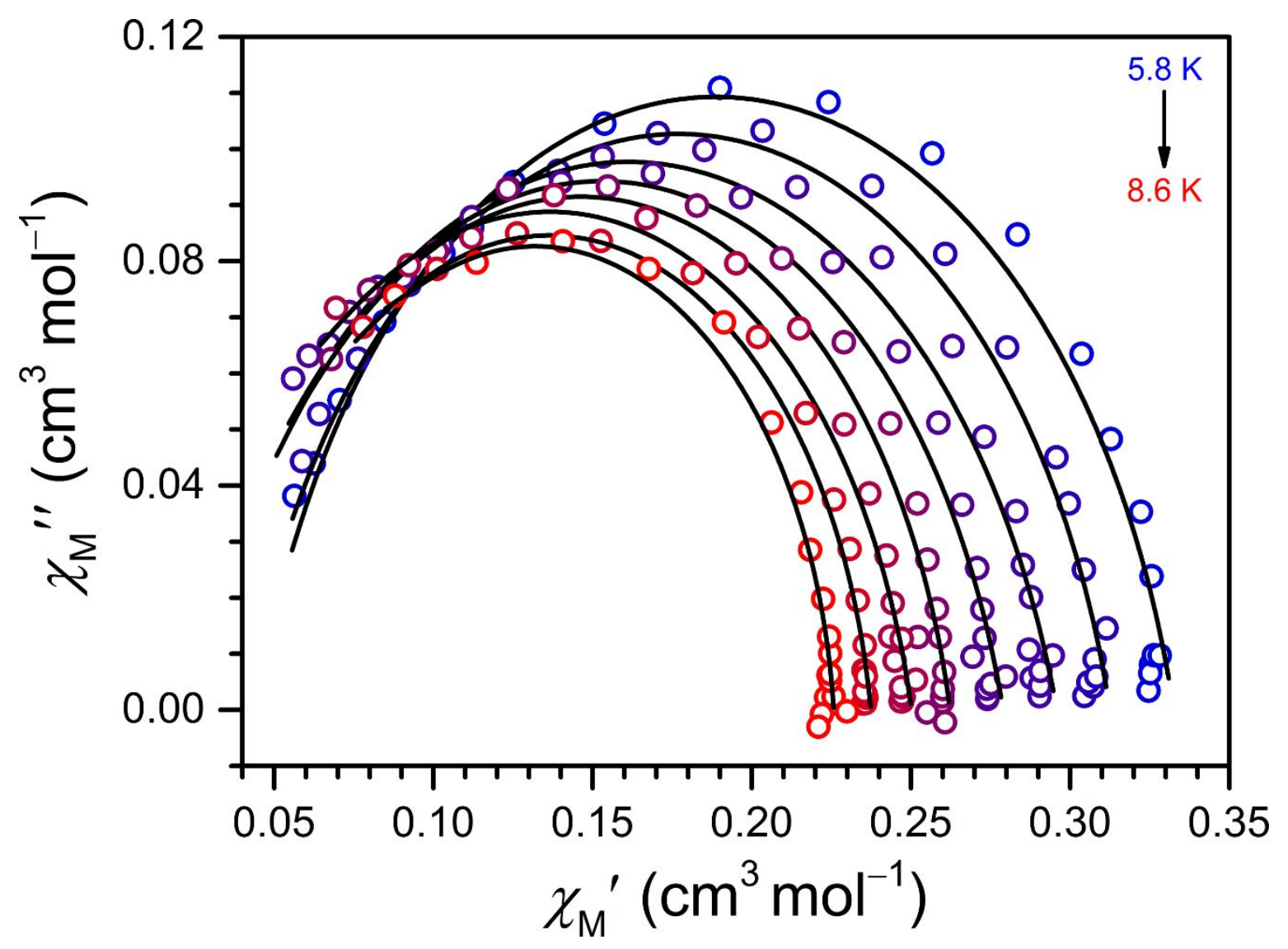

Figure S25. Cole-Cole plot for 3 constructed from data collected under an applied de field of 1200 Oe between 5.8 (blue) and $8.6 \mathrm{~K}$ (red). Colored circles represent experimental data and black lines indicate fits of the data using a generalized Debye model ${ }^{9-11} \mathrm{~s}$ 


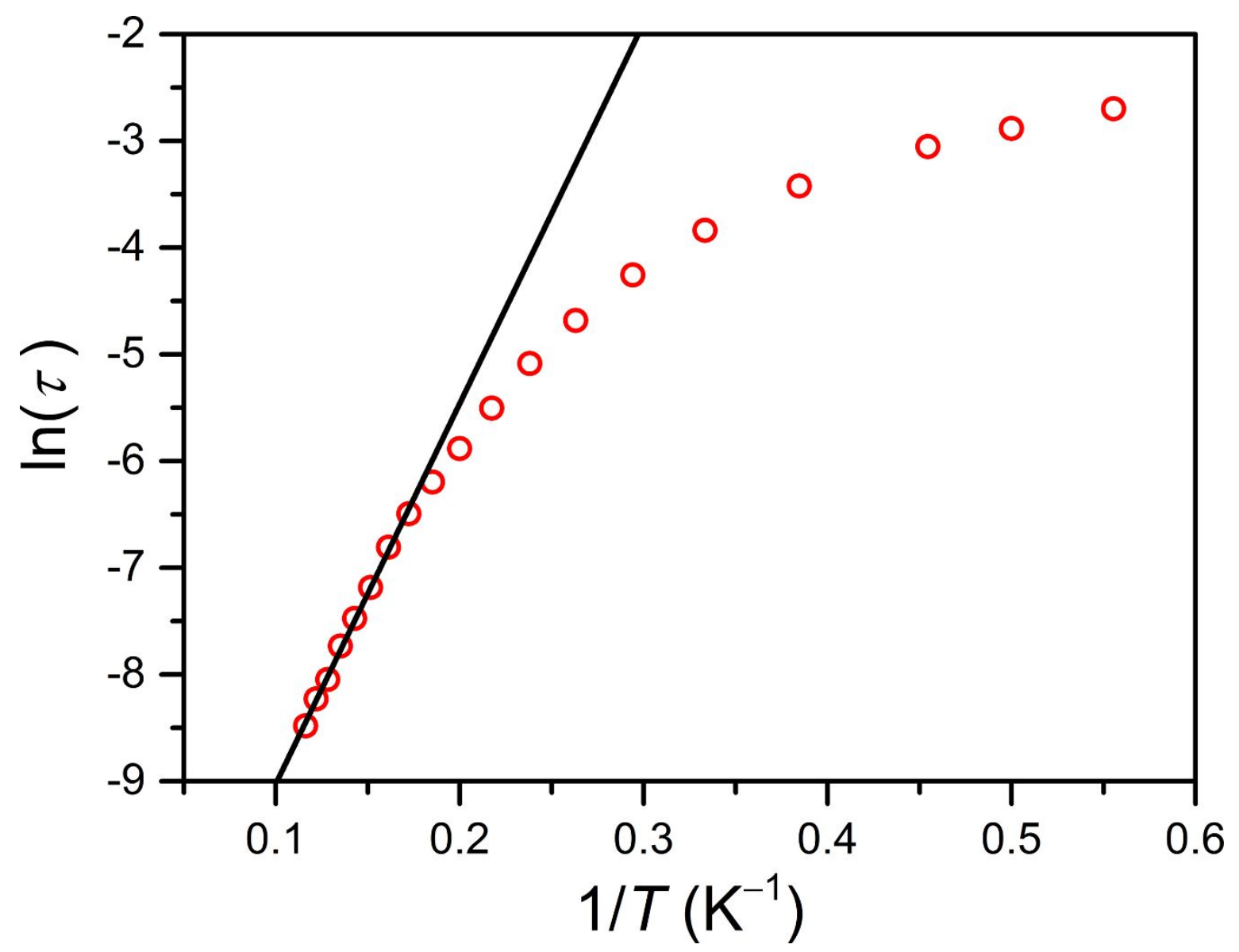

Figure S26. Arrhenius plot of relaxation time for $\mathbf{3}$ constructed from data collected under an applied dc field of 1200 Oe between 1.8 and $8.6 \mathrm{~K}$. Red circles represent experimental data and the black line indicates a linear fit to the data in the temperature range $5.8-8.6 \mathrm{~K}$ providing the following parameters: $U_{\text {eff }}=25(1) \mathrm{cm}^{-1} ; \tau_{0}=3.4(4) \times 10^{-6} \mathrm{~s}$. 


\section{Computational Details}

All calculations were performed using density functional theory as implemented in the Orca 3.0.3 computational software package. ${ }^{15}$ Evaluation of the electronic energies (single point energy) was done with def2-TZVP ${ }^{16}$ basis set for Fe, Mo, and the cyanide ligand, all other atoms were treated with the smaller def2-SVP basis set. Additionally, Grimme D317,18 dispersion corrections were included for all atoms. The Fe and Mo centers were treated with the DKH2 effective core potential to increase computational efficiency. It is well known that geometric changes have large effects on magnetic properties, therefore single point energies were taken from the experimentally determined crystal structure. ${ }^{19}$ The $S=3 / 2$ spin surface was modeled using the broken symmetry DFT (BS-DFT) as implemented in the Orca software package. Calculation of the magnetic exchange parameters $(J)$ were performed under all possible coupling regimes (see Table S1). ${ }^{20-24}$ Visualization of the magnetic orbitals were shown via a corresponding orbital transformation. ${ }^{25}$

\section{Results}

Evaluation of the single point energy of the experimental crystal structure on the $S=3 / 2$ broken symmetry surface shows significant $\beta$ spin density on Mo $(-0.5794)$ with partial delocalization of the $\mathrm{N}$ atom of the cyanide bridge $(-0.2083)$. The $\alpha$ spin density is localized on the Fe center (3.7539) with some spin contamination characteristic of a BS-DFT calculation. ${ }^{26}$ Visualization of the magnetic orbitals via a corresponding orbital transformation shows some delocalization on to the cyanide ligand with most of the spin density on the metal centers. The overlap of the magnetic pair is consistent with strong AF coupling at $S=0.30325$. 
Table S1. Calculated exchange coupling constants at the def2-TZVP level of theory.

\begin{tabular}{c|c}
$\boldsymbol{J}$ & Energy $\left(\mathrm{cm}^{-1}\right)$ \\
\hline $\boldsymbol{J}(1)$ & -119.20 \\
$\boldsymbol{J}(2)$ & -85.14 \\
$\boldsymbol{J}(3)$ & -181.50 \\
Experimental & -123
\end{tabular}

Three different equations have been proposed to properly calculate the exchange coupling constant $(J)$. The first method $J(1)$ was proposed by Noodleman et al., advocates for the weak interaction limit of coupling. $J(2)$ is the opposite extreme, the strong coupling regime. While $J(3)$ proposed by Yamaguchi covers everything in between and will reduce to $J(1)$ for the weak limit and $J(2)$ for strong coupling. All three proposed $J$ values are presented here for completeness. Each calculated $J$ has the correct sign for AF coupling. The magnitude for each calculated $J$ value is fairly consistent with the experimentally determined value of $-123 \mathrm{~cm}^{-1}$.

\section{Example Input File for BS-DFT Calculation}

The Flipspin/Final Ms method was used to calculate exchange coupling constants. Under the $\% \operatorname{scf}$ tab, the program is instructed to calculate the $S=5 / 2$ ferromagnetic electronic structure. Once the $S=5 / 2$ surface converges to a stable wavefunction the spin on the Mo (atom 0 by Orca numbering) is flipped and the final spin state is calculated at $S=3 / 2$ or $M_{\mathrm{s}}=1.5$. A previous calculation had already converged to the $S=5 / 2$ ferromagnetically coupled state and is read in using the \%moinp keyword. With the Flipspin/FinalMs method the exchange coupling constants are calculated and printed towards the bottom of the output file. Using the newGTO keyword next to Fe, Mo and the cyanide bridge atoms the larger def2-TZVP basis set is implemented for 
additionally basis set flexibility for the magnetically important atoms. All other atoms have the

\section{smaller def2-SVP double zeta basis set.}

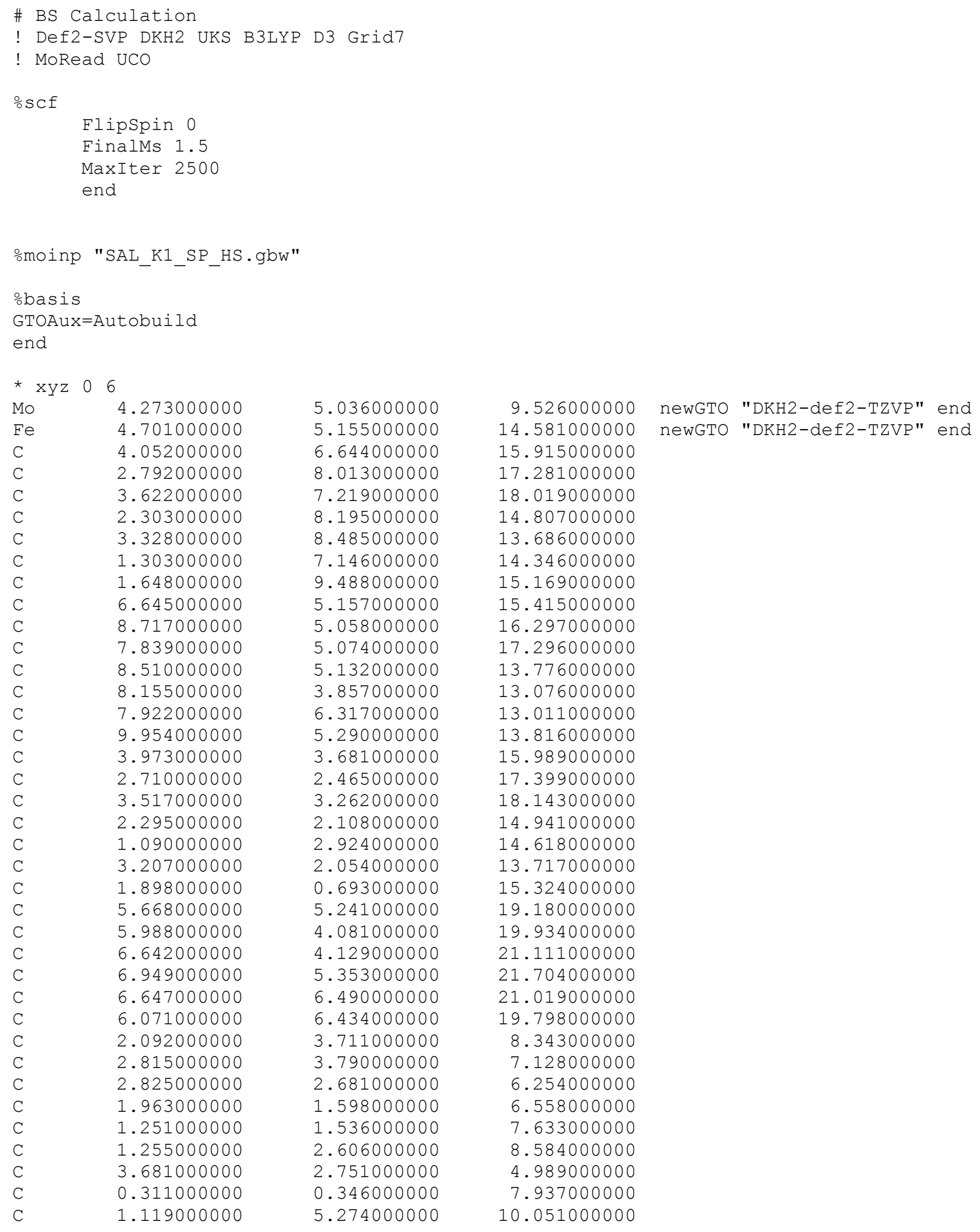

$\begin{array}{llll}\text { Mo } & 4.273000000 & 5.036000000 & 9.526000000 \\ \text { Fe } & 4.701000000 & 5.155000000 & 14.581000000 \\ \text { C } & 4.052000000 & 6.644000000 & 15.915000000 \\ \text { C } & 2.792000000 & 8.013000000 & 17.281000000 \\ \text { C } & 3.622000000 & 7.219000000 & 18.019000000 \\ \text { C } & 2.303000000 & 8.195000000 & 14.807000000 \\ \text { C } & 3.328000000 & 8.485000000 & 13.686000000 \\ \text { C } & 1.303000000 & 7.146000000 & 14.346000000 \\ \text { C } & 1.648000000 & 9.488000000 & 15.169000000 \\ \text { C } & 6.645000000 & 5.157000000 & 15.415000000 \\ \text { C } & 8.717000000 & 5.058000000 & 16.297000000 \\ \text { C } & 7.839000000 & 5.074000000 & 17.296000000 \\ \text { C } & 8.510000000 & 5.132000000 & 13.776000000 \\ \text { C } & 8.155000000 & 3.857000000 & 13.076000000 \\ \text { C } & 7.922000000 & 6.317000000 & 13.011000000 \\ \text { C } & 9.954000000 & 5.290000000 & 13.816000000 \\ \text { C } & 3.973000000 & 3.681000000 & 15.989000000 \\ \text { C } & 2.710000000 & 2.465000000 & 17.399000000 \\ \text { C } & 3.517000000 & 3.262000000 & 18.143000000 \\ \text { C } & 2.295000000 & 2.108000000 & 14.941000000 \\ \text { C } & 1.090000000 & 2.924000000 & 14.618000000 \\ \text { C } & 3.207000000 & 2.054000000 & 13.717000000 \\ \text { C } & 1.898000000 & 0.693000000 & 15.324000000 \\ \text { C } & 5.668000000 & 5.241000000 & 19.180000000 \\ \text { C } & 5.988000000 & 4.081000000 & 19.934000000 \\ \text { C } & 6.642000000 & 4.129000000 & 21.111000000 \\ \text { C } & 6.949000000 & 5.353000000 & 21.704000000 \\ \text { C } & 6.647000000 & 6.490000000 & 21.019000000 \\ \text { C } & 6.071000000 & 6.434000000 & 19.798000000 \\ \text { C } & 2.092000000 & 3.711000000 & 8.343000000 \\ \text { C } & 2.815000000 & 3.790000000 & 7.128000000 \\ \text { C } & 2.825000000 & 2.681000000 & 6.254000000 \\ \text { C } & 1.963000000 & 1.598000000 & 6.558000000 \\ \text { C } & 1.251000000 & 1.536000000 & 7.633000000 \\ \text { C } & 1.255000000 & 2.606000000 & 8.584000000 \\ \text { C } & 3.681000000 & 2.751000000 & 4.989000000 \\ \text { C } & 0.311000000 & 0.346000000 & 7.937000000 \\ \text { C } & 1.119000000 & 5.274000000 & 10.051000000\end{array}$

newGTO "DKH2-def2-TZVP" end newGTO "DKH2-def2-TZVP" end 


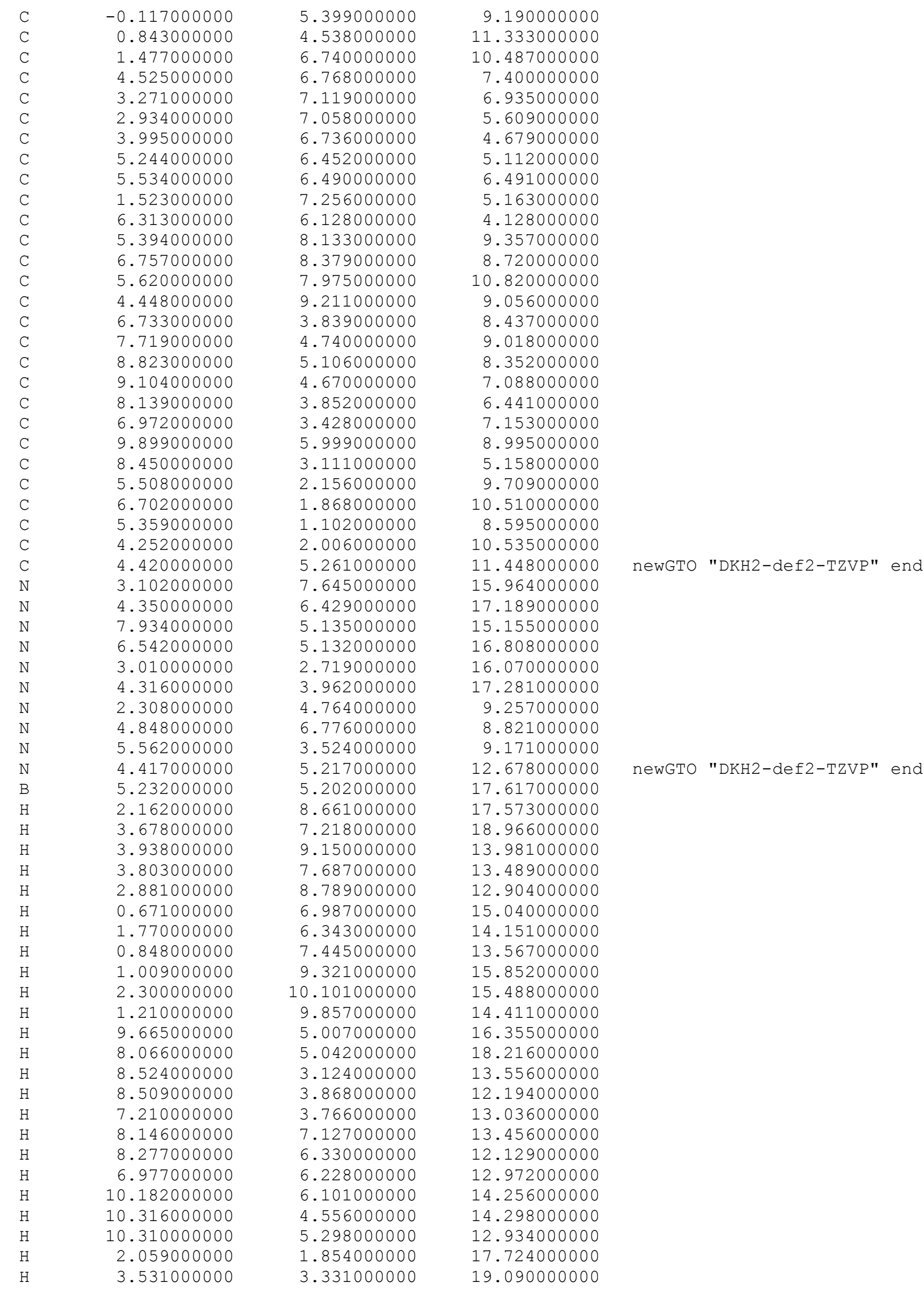




\begin{tabular}{|c|c|c|c|}
\hline $\mathrm{H}$ & 0.517000000 & 2.947000000 & 15.375000000 \\
\hline $\mathrm{H}$ & 1.359000000 & 3.809000000 & 14.398000000 \\
\hline $\mathrm{H}$ & 0.629000000 & 2.540000000 & 13.883000000 \\
\hline $\mathrm{H}$ & 3.973000000 & 1.531000000 & 13.919000000 \\
\hline $\mathrm{H}$ & 3.475000000 & 2.939000000 & 13.497000000 \\
\hline $\mathrm{H}$ & 2.747000000 & 1.670000000 & 12.980000000 \\
\hline $\mathrm{H}$ & 2.666000000 & 0.168000000 & 15.526000000 \\
\hline $\mathrm{H}$ & 1.339000000 & 0.739000000 & 16.089000000 \\
\hline $\mathrm{H}$ & 1.422000000 & 0.291000000 & 14.606000000 \\
\hline $\mathrm{H}$ & 5.728000000 & 3.239000000 & 19.580000000 \\
\hline $\mathrm{H}$ & 6.895000000 & 3.319000000 & 21.539000000 \\
\hline $\mathrm{H}$ & 7.368000000 & 5.391000000 & 22.557000000 \\
\hline $\mathrm{H}$ & 6.829000000 & 7.335000000 & 21.417000000 \\
\hline $\mathrm{H}$ & 5.952000000 & 7.242000000 & 19.310000000 \\
\hline $\mathrm{H}$ & 3.282000000 & 4.586000000 & 6.904000000 \\
\hline $\mathrm{H}$ & 1.916000000 & 0.883000000 & 5.934000000 \\
\hline $\mathrm{H}$ & 3.597000000 & 1.937000000 & 4.509000000 \\
\hline $\mathrm{H}$ & 4.592000000 & 2.887000000 & 5.223000000 \\
\hline $\mathrm{H}$ & 3.385000000 & 3.471000000 & 4.446000000 \\
\hline $\mathrm{H}$ & -0.104000000 & 0.528000000 & 8.771000000 \\
\hline $\mathrm{H}$ & 0.805000000 & -0.462000000 & 7.997000000 \\
\hline $\mathrm{H}$ & -0.355000000 & 0.261000000 & 7.264000000 \\
\hline $\mathrm{H}$ & 0.111000000 & 5.853000000 & 8.387000000 \\
\hline $\mathrm{H}$ & -0.776000000 & 5.896000000 & 9.657000000 \\
\hline $\mathrm{H}$ & -0.458000000 & 4.538000000 & 8.980000000 \\
\hline $\mathrm{H}$ & 1.644000000 & 4.476000000 & 11.838000000 \\
\hline $\mathrm{H}$ & 0.193000000 & 5.025000000 & 11.830000000 \\
\hline $\mathrm{H}$ & 0.514000000 & 3.667000000 & 11.151000000 \\
\hline $\mathrm{H}$ & 2.249000000 & 6.732000000 & 11.038000000 \\
\hline $\mathrm{H}$ & 0.747000000 & 7.114000000 & 10.966000000 \\
\hline $\mathrm{H}$ & 1.646000000 & 7.259000000 & 9.709000000 \\
\hline $\mathrm{H}$ & 2.624000000 & 7.415000000 & 7.564000000 \\
\hline $\mathrm{H}$ & 3.807000000 & 6.722000000 & 3.748000000 \\
\hline $\mathrm{H}$ & 6.420000000 & 6.340000000 & 6.799000000 \\
\hline $\mathrm{H}$ & 1.461000000 & 7.178000000 & 4.218000000 \\
\hline $\mathrm{H}$ & 1.233000000 & 8.122000000 & 5.429000000 \\
\hline $\mathrm{H}$ & 0.972000000 & 6.599000000 & 5.573000000 \\
\hline $\mathrm{H}$ & 7.123000000 & 5.962000000 & 4.595000000 \\
\hline $\mathrm{H}$ & 6.435000000 & 6.856000000 & 3.530000000 \\
\hline $\mathrm{H}$ & 6.066000000 & 5.353000000 & 3.635000000 \\
\hline $\mathrm{H}$ & 6.651000000 & 8.498000000 & 7.784000000 \\
\hline $\mathrm{H}$ & 7.158000000 & 9.155000000 & 9.093000000 \\
\hline $\mathrm{H}$ & 7.314000000 & 7.627000000 & 8.884000000 \\
\hline $\mathrm{H}$ & 4.780000000 & 7.831000000 & 11.239000000 \\
\hline $\mathrm{H}$ & 6.025000000 & 8.754000000 & 11.182000000 \\
\hline $\mathrm{H}$ & 6.181000000 & 7.224000000 & 10.973000000 \\
\hline $\mathrm{H}$ & 3.619000000 & 9.026000000 & 9.479000000 \\
\hline $\mathrm{H}$ & 4.780000000 & 10.048000000 & 9.361000000 \\
\hline $\mathrm{H}$ & 4.327000000 & 9.243000000 & 8.115000000 \\
\hline $\mathrm{H}$ & 7.559000000 & 5.098000000 & 9.883000000 \\
\hline $\mathrm{H}$ & 9.929000000 & 4.885000000 & 6.667000000 \\
\hline $\mathrm{H}$ & 6.350000000 & 2.847000000 & 6.732000000 \\
\hline $\mathrm{H}$ & 10.635000000 & 6.156000000 & 8.417000000 \\
\hline $\mathrm{H}$ & 10.204000000 & 5.565000000 & 9.785000000 \\
\hline $\mathrm{H}$ & 9.493000000 & 6.826000000 & 9.223000000 \\
\hline $\mathrm{H}$ & 7.696000000 & 2.625000000 & 4.848000000 \\
\hline $\mathrm{H}$ & 9.170000000 & 2.512000000 & 5.320000000 \\
\hline $\mathrm{H}$ & 8.710000000 & 3.746000000 & 4.501000000 \\
\hline $\mathrm{H}$ & 6.757000000 & 2.536000000 & 11.182000000 \\
\hline $\mathrm{H}$ & 6.639000000 & 1.011000000 & 10.916000000 \\
\hline $\mathrm{H}$ & 7.478000000 & 1.904000000 & 9.963000000 \\
\hline $\mathrm{H}$ & 4.579000000 & 1.288000000 & 8.081000000 \\
\hline $\mathrm{H}$ & 5.284000000 & 0.238000000 & 8.982000000 \\
\hline
\end{tabular}




$\begin{array}{lllr}\mathrm{H} & 6.123000000 & 1.129000000 & 8.031000000 \\ \mathrm{H} & 3.496000000 & 2.164000000 & 9.982000000 \\ \mathrm{H} & 4.261000000 & 2.636000000 & 11.245000000 \\ \mathrm{H} & 4.205000000 & 1.128000000 & 10.891000000 \\ \mathrm{H} & 0.722000000 & 2.561000000 & 9.370000000\end{array}$

\%pal nprocs 32 end 


\section{Crystallographic Information}

\section{$\mathrm{PhB}(\mathrm{tBuIm})_{3} \mathrm{FeOCH}_{3}$}

Empirical formula

Formula weight

Crystal color, shape, size

Temperature

Wavelength

Crystal system, space group

Unit cell dimensions

Volume

Z

Density (calculated)

Absorption coefficient

$\mathrm{F}(000)$

Data collection

Diffractometer

Theta range for data collection

Index ranges

Reflections collected

Independent reflections

Observed Reflections

Completeness to theta $=25.242^{\circ}$

Solution and Refinement

Absorption correction

Max. and min. transmission

Solution

Refinement method

Weighting scheme

Data / restraints / parameters

Goodness-of-fit on $\mathrm{F}^{2}$

Final $R$ indices $[\mathrm{I}>2 \sigma(\mathrm{I})]$

$\mathrm{R}$ indices (all data)

Largest diff. peak and hole

Twin details

Type, twin law

Twin element, domain ratio
C68.78 H103.55 B Fe Mo N10 O0.23

1236.66

black plate, $0.120 \times 0.110 \times 0.070 \mathrm{~mm}^{3}$

100(2) K

$0.71073 \AA$

Monoclinic, $\mathrm{P} 2{ }_{1} / \mathrm{c}$

$\mathrm{a}=20.9751(8) \AA$

$\alpha=90^{\circ}$.

$\mathrm{b}=16.3031(7) \AA$

$\beta=106.2869(12)^{\circ}$.

$\mathrm{c}=20.4833(6) \AA$

$\gamma=90^{\circ}$.

6723.4(4) $\AA^{3}$

4

$1.222 \mathrm{Mg} / \mathrm{m}^{3}$

$0.450 \mathrm{~mm}^{-1}$

2644

APEX II Kappa Duo, Bruker

1.699 to $27.710^{\circ}$.

$-12<=\mathrm{h}<=12,0<=\mathrm{k}<=23,0<=1<=21$

58368

$6756\left[\mathrm{R}_{\mathrm{int}}=0.0453\right]$

6155

$100.0 \%$

Semi-empirical from equivalents

0.745553 and 0.637415

Intrinsic methods

Full-matrix least-squares on $\mathrm{F}^{2}$

$\mathrm{w}=\left[\sigma^{2} \mathrm{Fo}^{2}+0.0517 \mathrm{P}^{2}+0.5276 \mathrm{P}\right]^{-1}$, with $\mathrm{P}=\left(\mathrm{Fo}^{2}+2 \mathrm{Fc}^{2}\right) / 3$

$6756 / 0 / 345$

1.151

$\mathrm{R} 1=0.0332, \mathrm{wR} 2=0.0936$

$\mathrm{R} 1=0.0398, \mathrm{wR} 2=0.0967$

0.529 and -0.234 e. $\AA^{-3}$

non-merohedral, 100,0 -1 0, -0.127 0 -1

$180^{\circ}$ rotation about 100 in real space, 52:48 


\section{$\operatorname{PhB}(\mathrm{tBuIm})_{3} \mathrm{FeF}(1)$}

Empirical formula

Formula weight

Crystal color, shape, size

Temperature

Wavelength

Crystal system, space group

Unit cell dimensions

Volume

Z

Density (calculated)

Absorption coefficient

$\mathrm{F}(000)$

Data collection

Diffractometer

Theta range for data collection

Index ranges

Reflections collected

Independent reflections

Observed Reflections

Completeness to theta $=25.817^{\circ}$

Solution and Refinement

Absorption correction

Max. and min. transmission

Solution

Refinement method

Weighting scheme

Data / restraints / parameters

Goodness-of-fit on $\mathrm{F}^{2}$

Final $\mathrm{R}$ indices $[\mathrm{I}>2 \operatorname{sigma}(\mathrm{I})]$

$\mathrm{R}$ indices (all data)

Largest diff. peak and hole
C29 H41 B1 F1 Fe1 N6 O0.50

567.34

colorless block, $0.250 \times 0.200 \times 0.150 \mathrm{~mm}^{3}$

$150 \mathrm{~K}$

$0.71073 \AA$

Triclinic, P-1

$\mathrm{a}=10.5503(9) \AA$

$\alpha=65.534(4)^{\circ}$.

$\mathrm{b}=12.1072(10) \AA$

$\beta=75.342(4)^{\circ}$.

$\mathrm{c}=13.3222(11) \AA$

$\gamma=83.721(4)^{\circ}$.

$1498.5(2) \AA^{3}$

2

$1.257 \mathrm{Mg} / \mathrm{m}^{3}$

$0.539 \mathrm{~mm}^{-1}$

602

Bruker Apex Kappa Duo, Bruker

1.725 to $26.616^{\circ}$.

$-13<=\mathrm{h}<=13,-15<=\mathrm{k}<=15,-16<=\mathrm{k}<=16$

39784

$6149[\mathrm{R}($ int $)=0.037]$

5797

$98.5 \%$

Semi-empirical from equivalents

0.92 and 0.90

Direct methods

Full-matrix least-squares on $\mathrm{F}^{2}$

$\mathrm{w}=\left[\sigma^{2} \mathrm{Fo}^{2}+\mathrm{AP}^{2}+\mathrm{BP}\right]^{-1}$, with

$\mathrm{P}=\left(\mathrm{Fo}^{2}+2 \mathrm{Fc}^{2}\right) / 3, \mathrm{~A}=0.060, \mathrm{~B}=1.705$

$6120 / 5 / 341$

1.0625

$\mathrm{R} 1=0.0449, \mathrm{wR} 2=0.1212$

$\mathrm{R} 1=0.0469, \mathrm{wR} 2=0.1227$

1.08 and -0.98 e. $\AA^{-3}$ 


\section{$\operatorname{PhB}(\mathrm{tBuIm})_{3} \mathrm{FeCN}$ (2)}

Empirical formula

Formula weight

Crystal color, shape, size

Temperature

Wavelength

Crystal system, space group

Unit cell dimensions

Volume

Z

Density (calculated)

Absorption coefficient

$\mathrm{F}(000)$

Data collection

Diffractometer

Theta range for data collection

Index ranges

Reflections collected

Independent reflections

Observed Reflections

Completeness to theta $=27.556^{\circ}$

Solution and Refinement

Absorption correction

Max. and min. transmission

Solution

Refinement method

Weighting scheme

Data / restraints / parameters

Goodness-of-fit on $\mathrm{F}^{2}$

Final $\mathrm{R}$ indices $[\mathrm{I}>2 \operatorname{sigma}(\mathrm{I})]$

$\mathrm{R}$ indices (all data)

Largest diff. peak and hole
C36 H54.00 B1 Fe1 N7 O2

683.53

red block, $0.200 \times 0.200 \times 0.100 \mathrm{~mm}^{3}$

$173 \mathrm{~K}$

$0.71073 \AA$

Orthorhombic, Pnma

$\mathrm{a}=21.4652(9) \AA$

$\alpha=90^{\circ}$.

$\mathrm{b}=17.9517(8) \AA$

$\beta=90^{\circ}$.

$\mathrm{c}=9.7390(4) \AA$

$\gamma=90^{\circ}$.

3752.8(3) $\AA^{3}$

4

$1.210 \mathrm{Mg} / \mathrm{m}^{3}$

$0.442 \mathrm{~mm}^{-1}$

1464.001

Bruker Apex Kappa Duo, Bruker

2.269 to $27.556^{\circ}$.

$-27<=\mathrm{h}<=27,-23<=\mathrm{k}<=23,-12<=\mathrm{l}<=12$

32796

$4472[\mathrm{R}($ int $)=0.029]$

4004

$99.7 \%$

Semi-empirical from equivalents

0.96 and 0.92

Direct methods

Full-matrix least-squares on $\mathrm{F}^{2}$

$\mathrm{w}=\left[\sigma^{2} \mathrm{Fo}^{2}+\mathrm{AP}^{2}+\mathrm{BP}\right]^{-1}$, with

$\mathrm{P}=\left(\mathrm{Fo}^{2}+2 \mathrm{Fc}^{2}\right) / 3, \mathrm{~A}=0.121, \mathrm{~B}=8.510$

4457 / 75 / 239

1.0140

$\mathrm{R} 1=0.0724, \mathrm{wR} 2=0.2083$

$\mathrm{R} 1=0.0771, \mathrm{wR} 2=0.2152$

1.58 and -1.10 e. $\AA^{-3}$ 
$\mathrm{PhB}\left({ }^{(\mathrm{BuIm}}\right)_{3} \mathrm{FeNCMo}\left(\mathrm{N}^{\mathrm{t} B u A r}\right)_{3}$ (3)

Empirical formula

Formula weight

Crystal color, shape, size

Temperature

Wavelength

Crystal system, space group

Unit cell dimensions

Volume

Z

Density (calculated)

Absorption coefficient

$\mathrm{F}(000)$

Data collection

Diffractometer

Detector

Theta range for data collection

Index ranges

Reflections collected

Independent reflections

Observed Reflections

Completeness to theta $=25.242^{\circ}$

Solution and Refinement

Absorption correction

Max. and min. transmission

Solution

Refinement method

Weighting scheme

Data / restraints / parameters

Goodness-of-fit on $\mathrm{F}^{2}$

Final $\mathrm{R}$ indices $[\mathrm{I}>2 \sigma(\mathrm{I})]$

$\mathrm{R}$ indices (all data)

Largest diff. peak and hole
C68.78 H103.55 B Fe Mo N10 O0.23

1236.66

black plate, $0.120 \times 0.110 \times 0.070 \mathrm{~mm}^{3}$

100(2) K

$0.71073 \AA$

Monoclinic, $\mathrm{P} 2{ }_{1} / \mathrm{c}$

$\mathrm{a}=20.9751(8) \AA$

$\alpha=90^{\circ}$.

$\mathrm{b}=16.3031(7) \AA$

$\beta=106.2869(12)^{\circ}$.

$\mathrm{c}=20.4833(6) \AA$

$\gamma=90^{\circ}$.

6723.4(4) $\AA^{3}$

4

$1.222 \mathrm{Mg} / \mathrm{m}^{3}$

$0.450 \mathrm{~mm}^{-1}$

2644

Venture D8, Bruker

PhotonIII

2.356 to $27.630^{\circ}$.

$-27<=\mathrm{h}<=27,-21<=\mathrm{k}<=21,-25<=\mathrm{l}<=26$

333403

$15536[$ Rint $=0.1392]$

12280

$99.9 \%$

Semi-empirical from equivalents

0.7358 and 0.6958

Intrinsic methods

Full-matrix least-squares on $\mathrm{F}^{2}$

$\mathrm{w}=\left[\sigma^{2} \mathrm{Fo}^{2}+\mathrm{AP}^{2}+\mathrm{BP}\right]^{-1}$, with

$\mathrm{P}=\left(\mathrm{Fo}^{2}+2 \mathrm{Fc}^{2}\right) / 3, \mathrm{~A}=0.0207, \mathrm{~B}=8.5006$

$15536 / 133 / 799$

1.048

$\mathrm{R} 1=0.0411, \mathrm{wR} 2=0.0787$

$\mathrm{R} 1=0.0606, \mathrm{wR} 2=0.0880$

0.608 and -0.638 e. $\AA^{-3}$ 


\section{References}

1. Scepaniak, J. J.; Fulton, M. D.; Bontchev, R. P.; Duesler, E. N.; Kirk, M. L.; Smith, J. M. Structural and Spectroscopic Characterization of an Electrophilic Iron Nitrido Complex. $J$. Am. Chem. Soc. 2008, 130, 10515-10517.

2. Laplaza, C. E.; Cummins, C. C. Dinitrogen Cleavage by a Three-Coordinate Molybdenum (III) Complex. Science 1995, 268, 861-863.

3. Figueroa, J. S.; Piro, N. A.; Clough, C. R.; Cummins, C. C. A Nitridoniobium(V) Reagent That Effects Acid Chloride to Organic Nitrile Conversion: Synthesis via Heterodinuclear (Nb/Mo) Dinitrogen Cleavage, Mechanistic Insights, and Recycling. J. Am. Chem. Soc. 2006, 128, 940-950.

4. $\quad$ Peters, J. C.; Cherry, J.-P. F.; Thomas, J. C.; Baraldo, L. M.; Mindiola, D. J.; Davis, W. M.; Cummins, C. C. Redox-Catalyzed Binding of Dinitrogen by Molybdenum N-tertHydrocarbylanilide Complexes: Implications for Dinitrogen Functionalization and Reductive Cleavage. J. Am. Chem. Soc. 1999, 121, 10053-10067.

5. Ding, M.; Rouzières, M.; Losovyj, Y.; Pink, M.; Clérac, R.; Smith, J. M. Partial Nitrogen Atom Transfer: A New Synthetic Tool to Design Single-Molecule Magnets. Inorg. Chem. 2015, 54, 9075-9080.

6. Peters, J. C.; Baraldo, L. M.; Baker, T. A.; Johnson, A. R.; Cummins, C. C. Dimolybdenum$\mu$-cyanide Complexes Supported by N-tert-butylanilide Ligation: In Pursuit of Cyanide Reductive Cleavage. J. Organomet. Chem. 1999, 591, 24-35.

7. Johnson, A. R.; Davis, W. M.; Cummins, C. C.; Serron, S.; Nolan, S. P.; Musaev, D. G.; Morokuma, K. Four-Coordinate Molybdenum Chalcogenide Complexes Relevant to Nitrous Oxide N-N Bond Cleavage by Three-Coordinate Molybdenum(III): Synthesis, Characterization, Reactivity, and Thermochemistry. J. Am. Chem. Soc. 1998, 120, 20712085.

8. Sceats, E. L.; Figueroa, J. S.; Cummins, C. C.; Loening, N. M.; Van der Wel, P.; Griffin, R. G. Complexes Obtained by Electrophilic Attack on a Dinitrogen-derived Terminal Molybdenum Nitride: Electronic Structure Analysis by Solid State CP/MAS ${ }^{15}$ NMR in Combination with DFT Calculations. Polyhedron 2004, 23, 2751-2768.

9. Cole, K. S.; Cole, R. H. Dispersion and Absorption in Dielectrics I. Alternating Current Characteristics. J. Chem. Phys. 1941, 9, 341-351.

10. Boettcher, C. J. F. Theory of Electric Polarisation; Elsevier: Amsterdam, 1952.

11. Aubin, S. M. J.; Sun, Z.; Pardi, L.; Krzystek, J.; Folting, K.; Brunel, L.-C.; Rheingold, A. L.; Christou, G.; Hendrickson, D. N. Reduced Anionic $\mathrm{Mn}_{12}$ Molecules with Half-Integer Ground States as Single-Molecule Magnets. Inorg. Chem. 1999, 38, 5329-5340.

12. Bain, G. A.; Berry, J. F. Diamagnetic Corrections and Pascal's Constants. J. Chem. Educ. 2008, 85, 532-536.

13. Tregenna-Piggott, P. L. W. MagProp (part of the NIST DAVE software suite), version 2.5; 2008, http://www.ncnr.nist.gov/dave.

14. Azuah, R. T.; Kneller, L. R.; Qiu, Y.; Tregenna-Piggott, P. L. W.; Brown, C. M.; Copley, J. R. D.; Dimeo, R. M. DAVE: A Comprehensive Software Suite for the Reduction, Visualization, and Analysis of Low Energy Neutron Spectroscopic Data. J. Res. Natl. Inst. Stand. Technol. 2009, 114, 341-358.

15. Neese, F. The ORCA program system. WIREs Comput. Mol. Sci. 2012, 2, 73-78. 
16. Pantazis, D. A.; Chen, X.-Y.; Landis, C. R.; Neese, F. All-Electron Scalar Relativistic Basis Sets for Third-Row Transition Metal Atoms. J. Chem. Theory Comput. 2008, 4, 908-919.

17. Grimme, S.; Ehrlich, S.; Goerigk, L. Effect of the Damping Function in Dispersion Corrected Density Functional Theory. J. Comput. Chem. 2011, 32, 1456-1465.

18. Grimme, S.; Antony, J.; Ehrlich, S.; Krieg, H. A Consistent and Accurate Ab Initio Parametrization of Density Functional Dispersion Correction (DFT-D) for the 94 Elements H-Pu. J. Chem. Phys. 2010, 132, 154104.

19. Reger, D. L.; Pascui, A. E.; Smith, M. D.; Jezierska, J.; Ozarowski, A. Syntheses, Structural, Magnetic, and Electron Paramagnetic Resonance Studies of Monobridged Cyanide and Azide Dinuclear Copper(II) Complexes: Antiferromagnetic Superexchange Interactions. Inorg. Chem. 2015, 54, 1487-1500.

20. Ginsberg, A. P. Magnetic Exchange in Transition Metal Complexes. 12. Calculation of Cluster Exchange Coupling Constants with the Xa-Scattered Wave Method. J. Am. Chem. Soc. 1980, 102, 111-117.

21. Noodleman, L. Valence Bond Description of Antiferromagnetic Coupling in Transition Metal Dimers. J. Chem. Phys. 1981, 74, 5737-5743.

22. Noodleman, L.; Davidson, E. R. Ligand Spin Polarization and Antiferromagnetic Coupling in Transition Metal Dimers. Chem. Phys. 1986, 109, 131-143.

23. Bencini, A.; Gatteschi, D. X $\alpha-\mathrm{SW}$ Calculations of the Electronic Structure and Magnetic Properties of Weakly Coupled Transition-Metal Clusters. The $\left[\mathrm{Cu}_{2} \mathrm{Cl}_{6}\right]^{2-}$ Dimers. J. Am. Chem. Soc. 1986, 108, 5763-5771.

24. Soda, T.; Kitagawa, Y.; Onishi, T.; Takano, Y.; Shigeta, Y.; Nagao, H.; Yoshioka, Y.; Yamaguchi, K. Ab Initio Computations of Effective Exchange Integrals for $\mathrm{H}-\mathrm{H}, \mathrm{H}-\mathrm{He}-\mathrm{H}$ and $\mathrm{Mn}_{2} \mathrm{O}_{2}$ Complex: Comparison of Broken-Symmetry Approaches. Chem. Phys. Lett. 2000, 319, 223-230.

25. Amos, A. T.; Hall, G. G. Single Determinant Wave Functions. Proc. Royal Soc. Lond. A 1961, 263, 483-493.

26. Neese, F. Prediction of Molecular Properties and Molecular Spectroscopy with Density Functional Theory: From Fundamental Theory to Exchange-coupling. Coord. Chem. Rev. 2009, 253, 526-563. 